\title{
A COMPREHENSIVE STUDY OF INFRARED OH PROMPT EMISSION IN TWO COMETS. I. OBSERVATIONS AND EFFECTIVE $g$-FACTORS
}

\author{
Boncho P. Bonev, ${ }^{1,2}$ Michael J. Mumma, ${ }^{1}$ Michael A. DiSanti, ${ }^{1}$ Neil Dello Russo, ${ }^{3}$ Karen Magee-Sauer, ${ }^{4}$ \\ Richard S. Ellis, ${ }^{5}$ and Daniel P. Stark ${ }^{5}$ \\ Received 2006 May 18; accepted 2006 August 9
}

\begin{abstract}
We present high-dispersion infrared spectra of hydroxyl $(\mathrm{OH})$ in comets $\mathrm{C} / 2000 \mathrm{WM}_{1}$ (LINEAR) and C/2004 Q2 (Machholz), acquired with the Near Infrared Echelle Spectrograph at the Keck Observatory atop Mauna Kea, Hawaii. Most of these rovibrational transitions result from photodissociative excitation of $\mathrm{H}_{2} \mathrm{O}$ giving rise to $\mathrm{OH}$ "prompt" emission. We present calibrated emission efficiencies (equivalent $g$-factors, measured in $\mathrm{OH}$ photons $\mathrm{s}^{-1}$ $\left[\mathrm{H}_{2} \mathrm{O} \text { molecule }\right]^{-1}$ ) for more than $20 \mathrm{OH}$ lines sampled in these two comets. The $\mathrm{OH}$ transitions analyzed cover a broad range of rotational excitation. This infrared database for $\mathrm{OH}$ can be used in two principal ways: (1) as an indirect tool for obtaining water production in comets simultaneously with the production of other parent volatiles, even when direct detections of $\mathrm{H}_{2} \mathrm{O}$ are not available; and (2) as an observational constraint to models predicting the rotational distribution of rovibrationally excited $\mathrm{OH}$ produced by water photolysis.
\end{abstract}

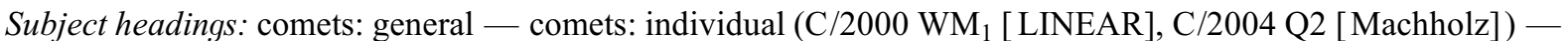
infrared: solar system - molecular data

Online material: color figures

\section{INTRODUCTION}

Since its identification in UV spectra of comet Cunningham (C/1940 R2; Swings et al. 1941), OH has been among the most extensively observed species in cometary atmospheres (see the review by Feldman et al. 2004). Historically, these data have provided important indirect evidence that water (the principal $\mathrm{OH}$ precursor) is the dominant volatile constituent of the nuclei of active comets (see Festou et al. 2004; Delsemme 1998). This notion was subsequently confirmed by direct detections of $\mathrm{H}_{2} \mathrm{O}$ in comet Halley (Mumma et al. 1986; Combes et al. 1986) and in many comets since then.

Water production has been quantified from $\mathrm{OH}$ data (UV and radio) for about 100 comets (Festou et al. 2004). OH fluorescent emission in the $A^{2} \Sigma-X^{2} \Pi$ system (near $308.5 \mathrm{~nm}$ ) has been extensively monitored using narrowband photometry and highresolution spectroscopy. One of the largest surveys is a groundbased taxonomic study of 85 comets, based on narrowband photometry of $\mathrm{OH}$ and other species (A'Hearn et al. 1995). The $A-X$ system was detected in a high-resolution spectroscopic survey of more than 50 comets observed with the International Ultraviolet Explorer (IUE; e.g., Festou \& Feldman 1987; Budzien et al. 1994), and spatial-spectral measurements of the $A-X$ emission band were acquired with the Space Telescope Imaging Spectrograph on the Hubble Space Telescope (HST; e.g., Feldman 1997; Weaver et al. 1999).

\footnotetext{
${ }^{1}$ Solar System Exploration Division, Code 693, NASA Goddard Space Flight Center, Greenbelt, MD 20771; bbonev@ssedmail.gsfc.nasa.gov.

2 Department of Physics and Astronomy, Ritter Astrophysical Research Center, University of Toledo, Toledo, $\mathrm{OH}$ 43606; current address: Department of Physics, Catholic University of America, Washington, DC 20064.

3 Space Department, Planetary Exploration Group, Applied Physics Laboratory, Johns Hopkins University, 11100 Johns Hopkins Road, Laurel, MD 20723-6099.

${ }^{4}$ Department of Physics and Astronomy, Rowan University, Glassboro, NJ 08028-1701.

5 Department of Astronomy, California Institute of Technology, Mail Code 105-24, 1200 East California Boulevard, Pasadena, CA 91125.
}

Since the mid-1970s, measurements of the $18 \mathrm{~cm}$ lines of hydroxyl at high-velocity resolution have provided information on the velocity and spatial asymmetries of outflowing gas and on collisional quenching of the maser inversion pumped by ultraviolet fluorescence (e.g., Despois et al. 1981; Bockelée-Morvan et al. 1990; Colom et al. 1997; Schloerb et al. 1997). Crovisier et al. $(2002 \mathrm{a}, 2002 \mathrm{~b})$ reviewed results for more than 50 comets observed at the Nançay radio observatory.

Recently, new insights have emerged from infrared spectra of $\mathrm{OH}$ acquired with echelle grating spectrometers that combine high spectral resolving power $(\lambda / \Delta \lambda>20,000)$, large spectral grasp, and high sensitivity. Since Hyakutake (C/1996 B2), cometary $\mathrm{OH}$ has been routinely detected via emission in its rovibrational transitions at wavelengths ranging from 2.9 to $3.7 \mu \mathrm{m}$ (e.g., Brooke et al. 1996; Magee-Sauer et al. 1999, 2002; Mumma et al. 2001; Gibb et al. 2003; Kawakita et al. 2005). In 1999, the cross-dispersed Near Infrared Echelle Spectrograph (NIRSPEC; McLean et al. 1998) was commissioned at Keck II, permitting for the first time simultaneous detection (within a single instrument setting) of the parent $\left(\mathrm{H}_{2} \mathrm{O}\right)$ and the daughter fragment $(\mathrm{OH})$.

Many OH lines were detected in comet C/1999 H1 (Lee) with NIRSPEC (Mumma et al. 2001). These authors discussed the excitation mechanism (see $\S 4$ ) for the observed $\mathrm{OH}$ emissions, and they suggested an empirical approach in their quantitative analysis for the purpose of deriving $\mathrm{H}_{2} \mathrm{O}$ production rates in future comets. This approach was subsequently fully developed and applied to one $\mathrm{OH}$ "quadruplet" (near $3046 \mathrm{~cm}^{-1}$; Bonev et al. 2004, hereafter B04).

This paper is the first part of a comprehensive study of infrared $\mathrm{OH}$ emission in two comets. We present calibrated emission efficiencies (equivalent $g$-factors) for $\mathrm{OH}$ and describe their application for quantifying $\mathrm{H}_{2} \mathrm{O}$ production simultaneously with various native species of key interest. In Bonev \& Mumma (2006, hereafter Paper II) we demonstrate their relevance for providing insights into the unimolecular dissociation of $\mathrm{H}_{2} \mathrm{O}$, revealed through the rotational population distribution of vibrationally excited and highly rotationally excited $\mathrm{OH}$ products. 


\section{SIMULTANEOUS DETECTIONS OF $\mathrm{H}_{2} \mathrm{O}$, OTHER PARENT VOLATILES, AND OH WITH KECK II NIRSPEC}

NIRSPEC is a cross-dispersed echelle grating spectrometer that delivers high spectral resolving power $(\lambda / \Delta \lambda \sim 24,000)$ when used with a 0 ."43 wide entrance slit. Equipped with a $1024 \times$ $1024 \mathrm{InSb}$ detector array, six spectral orders are simultaneously sampled in the $L$ band $(2.9-4.0 \mu \mathrm{m})$, and about $40 \mathrm{~cm}^{-1}$ of each order are encompassed at once. The main advantage of NIRSPEC is its ability to measure many species of interest simultaneously and with high sensitivity. The molecular species commonly observed can in most cases be sampled within only two or three instrument settings in the $L$ band and one in the $M$ band (4.4$5.5 \mu \mathrm{m})$. These include $\mathrm{H}_{2} \mathrm{O}$ and its dissociation product $(\mathrm{OH})$, hydrocarbons $\left(\mathrm{CH}_{4}, \mathrm{C}_{2} \mathrm{H}_{2}\right.$, and $\left.\mathrm{C}_{2} \mathrm{H}_{6}\right)$, nitriles $\left(\mathrm{HCN}\right.$ and $\left.\mathrm{NH}_{3}\right)$, and oxygen-bearing molecules $\left(\mathrm{CO}, \mathrm{H}_{2} \mathrm{CO}\right.$, and $\left.\mathrm{CH}_{3} \mathrm{OH}\right)$. At least one representative of each group is sampled within the spectral setting (KL2) shown in Figure 1.

Here we present detections of multiple $\mathrm{OH}$ lines from obser-

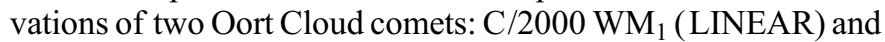
C/2004 Q2 (Machholz). These are very high quality data sets (see discussion in Bonev 2005), which we consider most appropriate (within our database) for deriving molecular parameters for $\mathrm{OH}$. Table 1 shows condensed observing logs for the two objects. The signal in each individual frame is dominated by background thermal continuum and molecular sky emission (Fig. 1a). The telescope was nodded $\pm 6^{\prime \prime}$ along the slit, in a standard ABBA sequence. The difference frame $(\mathrm{A}-\mathrm{B})$ cancels the thermal sky and telescope emission via pixel-by-pixel subtraction and reveals the comet signal at the A and B positions (Fig. 1b).

Algorithms for data processing and flux calibration (based on observations of standard stars) were developed specifically for our comet observations and are described elsewhere (Dello Russo et al. 1998, 2000; Magee-Sauer et al. 1999; DiSanti et al. 2001; Mumma et al. 2001; Gibb et al. 2003). The most detailed and upto-date discussion is given by Bonev (2005), who reviews all the important steps leading from data acquisition to flux calibrated spectra.

Figures $2 a-2 i$ show spectra from $\mathrm{C} / 2000 \mathrm{WM}_{1}$ and $\mathrm{C} / 2004$ Q2, the terrestrial atmospheric transmittance convolved to the instrumental resolution, and the cometary residuals. All spectra belong to the KL2 setting (Fig. 1); OH lines from order 22 ( 2894-2890 $\mathrm{cm}^{-1}$ ) are likely blended with $\mathrm{CH}_{3} \mathrm{OH}$ and are not presented here, because the contribution of methanol has not been quantified. Atmospheric transmittance was modeled using the spectral synthesis program (Kunde \& Maguire 1974) that accesses the HITRAN molecular database (Rothman et al. 1992).

The spectra are presented in a two-panel graphic (Figs. $2 a-2 i$ ). The top panels show the measured cometary spectrum and a bestfit atmospheric transmittance model normalized to the continuum. Cometary emissions are seen against these optimized synthetic spectra. The bottom panels show residual spectra after subtraction of continuum, multiplied by the telluric transmittance function (see Bonev 2005). The residuals reveal cometary emission from various species: $\mathrm{H}_{2} \mathrm{O}$ is seen in "hot-band" (nonresonant) fluorescence, mostly in order 26; the commonly detected lines of $\mathrm{HCN}$ appear in order 25; the $\mathrm{CH}_{4}$ low-excitation $R$-branch lines are seen in order 23; and part of the spectral range for $\mathrm{H}_{2} \mathrm{CO}$ (including the $\nu_{1} Q$-branch) appears in order 21 .

In this "spectral gallery," $\mathrm{OH}$ lines often occur near emissions of species of primary interest in astronomy and astrobiology, such as $\mathrm{H}_{2} \mathrm{CO}, \mathrm{CH}_{4}$, and $\mathrm{HCN}$. If $\mathrm{OH}$ emission can be established as a proxy for $\mathrm{H}_{2} \mathrm{O}$ production, this proximity would permit water and the trace constituents to be quantified simultaneously even when direct $\mathrm{H}_{2} \mathrm{O}$ detections are not available.

\section{OH ROVIBRATIONAL TRANSITIONS}

The $\mathrm{OH}$ lines in Figure 2 represent rovibrational transitions in the ground electronic state $\left(X^{2} \Pi\right)$ of $\mathrm{OH}$ (Dieke \& Crosswhite 1962). The types of rotational energy levels of the ${ }^{2} \Pi$ state are presented schematically in Figure 3. The interaction between the total electronic spin and orbital angular momentum (spin-orbit coupling) gives rise to the ${ }^{2} \Pi_{1 / 2}$ and ${ }^{2} \Pi_{3 / 2}$ "ladders." In the notation of Hund's case (b) (i.e., fast molecular rotation; see Herzberg 1988), a given ${ }^{2} \Pi$ level is split into two states, with rotational quantum numbers $(J) N-\frac{1}{2}$ and $N+\frac{1}{2}$, where $N$ represents the total angular momentum apart from spin. Another splitting (the $\Lambda$-type doubling) is caused by the interaction between the rotation of the molecule and the internuclear component of the electronic orbital angular momentum. The split levels are designated as "+" and "-" depending on the parity of the overall wave function. The series of $\Lambda$-doublet levels in which the electronic wave function at high $J$ (Hund's case [b]) is symmetric and antisymmetric with respect to reflection are designated, respectively, as $\Pi\left(A^{\prime}\right)$ and $\Pi\left(A^{\prime \prime}\right)$ (for $\Lambda=1$ ) for all values of $J$ (Alexander et al. 1988). ${ }^{6}$

Two rotational levels with the same value of $N\left(J_{1}=N+\frac{1}{2}\right.$ and $J_{2}=N-\frac{1}{2}$; see Fig. 3) lie close together. Because of the $\Lambda$-doubling of each level, $\mathrm{OH}$ lines are commonly detected in quadruplets. The most important selection rules to consider are $\Delta J=0, \pm 1$ (we observe lines with $\Delta J=-1$ ), and “+” $\leftrightarrow$ “_" (Dieke \& Crosswhite 1962; Herzberg 1988).

Quantitatively analyzed $\mathrm{OH}$ transitions and top-of-theatmosphere line fluxes for $\mathrm{C} / 2000 \mathrm{WM}_{1}$ and $\mathrm{C} / 2004 \mathrm{Q} 2$ are given in Table 2. Rest frequencies are taken from Maillard et al. (1976) and are in very good agreement with the results of Abrams et al. (1990). Our line notation follows the former work, in the following form: P11.5 $2^{+}$; P12.5 $1^{-}$. The "P" designates the $P$-branch of the vibrational band; $J^{\prime \prime}=11.5\left(J^{\prime}=10.5\right)$ for the first line listed and $J^{\prime \prime}=12.5\left(J^{\prime}=11.5\right)$ for the second; and " 1 " designates ${ }^{2} \Pi_{3 / 2}$ while " 2 " designates ${ }^{2} \Pi_{1 / 2}$. The parity of the lower level is shown (e.g., + ), with the reminder that the upper states (in $v^{\prime}=1$ ) have the opposite parity according to the selection rule.

\section{EXCITATION MECHANISM: $\mathrm{H}_{2} \mathrm{O}$ PHOTODISSOCIATION AND OH PROMPT EMISSION}

Low rotational levels of $\mathrm{OH}\left(X^{2} \Pi, v^{\prime}=1\right)$ can be populated via direct IR solar pumping of $\mathrm{OH}$ itself (through the fundamental vibrational band) and via UV fluorescence through the $A^{2} \Sigma^{+}$states, followed by cascade into $X^{2} \Pi\left(v^{\prime}=1\right)$ (Schleicher $\&$ A'Hearn 1982). Weaver \& Mumma (1984) estimated fluorescence efficiencies for infrared pumping alone, while Schleicher \& A'Hearn (1988) considered both UV and infrared pumping for $\mathrm{OH}$ rovibrational transitions with $N^{\prime} \leqslant 5$. These authors found that inclusion of the $N^{\prime}=5$ levels had a negligible effect on the predicted line intensities. The strongest fluorescent "doublets" predicted by these papers either are not sampled in our study (Q1.5 $1^{+}$and $1^{-}$at $\sim 3568 \mathrm{~cm}^{-1} ; \mathrm{P} 2.51^{+}$and $1^{-}$at $\sim 3485 \mathrm{~cm}^{-1}$ )

\footnotetext{
6 Solar UV fluorescence causes inversion (or anti-inversion, depending on the comet heliocentric velocity) in the populations of the $\Lambda$-doublet levels of the ground state of $\mathrm{OH}$. As a result, this $\Lambda$-doublet acts as a weak maser amplifying (or attenuating) the cosmic background radiation at $18 \mathrm{~cm}$, giving rise to $\mathrm{OH}$ emission (or absorption) at this wavelength. The $\mathrm{OH} 18 \mathrm{~cm}$ lines have been widely used to derive $\mathrm{H}_{2} \mathrm{O}$ production rates in comets (see Despois et al. 1981; Schleicher \& A'Hearn 1988). Quantitative understanding of these lines involves a hyperfine splitting of each $\Lambda$-doublet level, not shown on Fig. 3.
} 


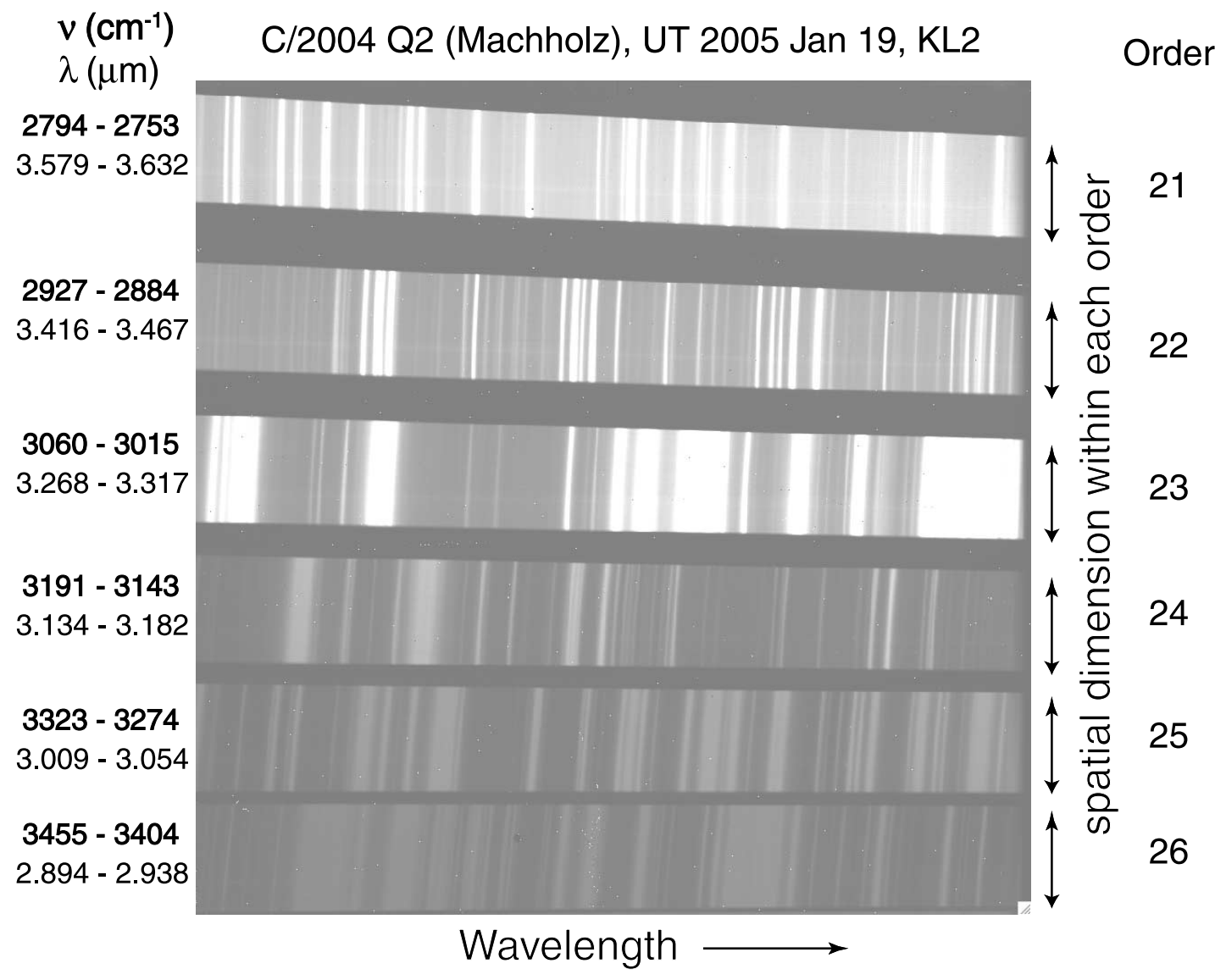

Fig. $1 a$

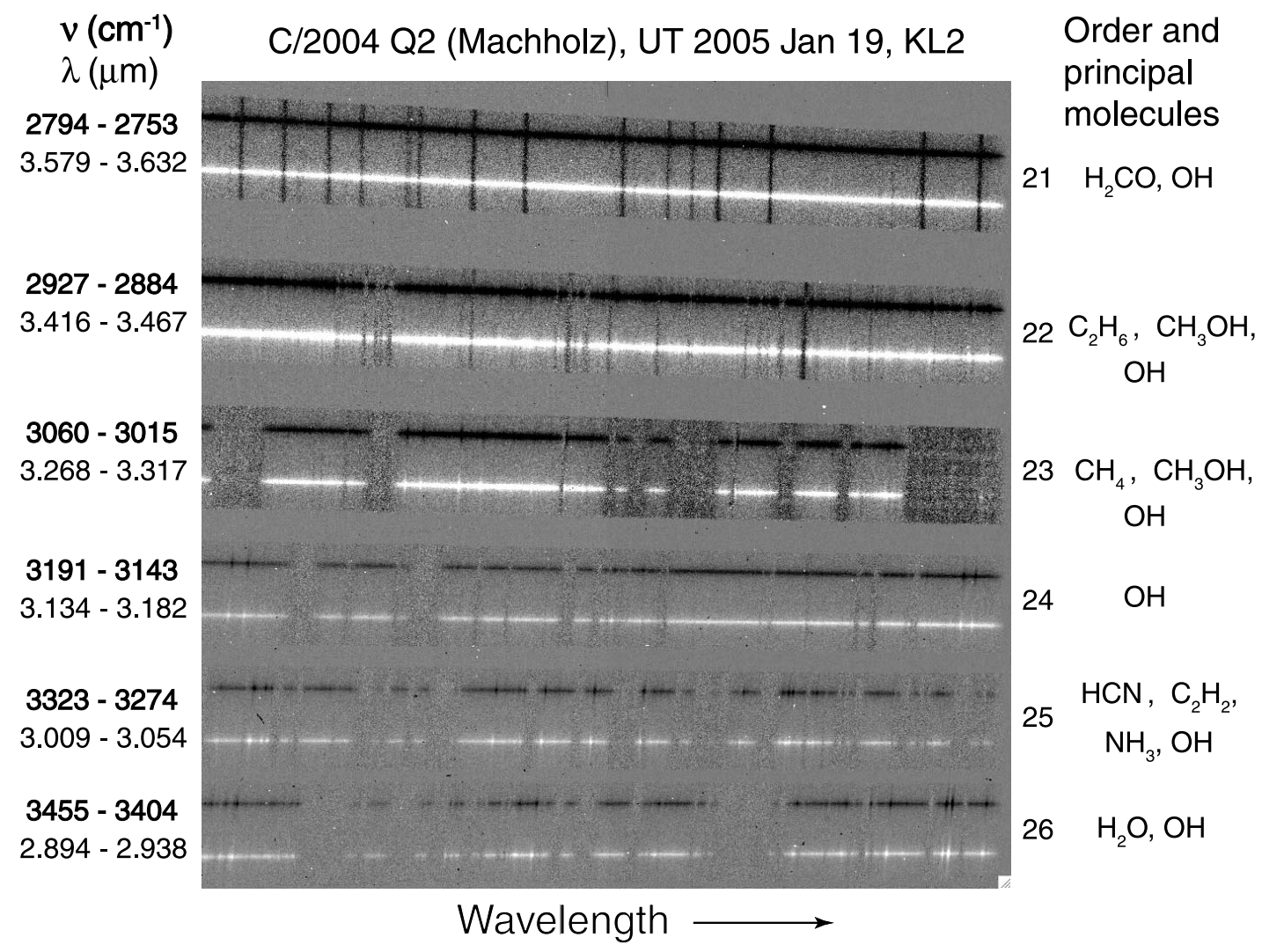

FIG. $1 b$

FIG. 1.- Introduction to NIRSPEC data. (a) "Raw" NIRSPEC echellogram: high-resolution $(\lambda / \delta \lambda \sim 24,000)$ echelle spectrograph disperses the signal in the "horizontal" dimension (spectral dimension). A low-resolution cross disperser operating perpendicular to the echelle separates the echelle orders. The "vertical" dimension within a given order is the spatial one, corresponding to the length of the entrance slit (the slit used is $24^{\prime \prime}$ long and 0.43 wide). The signal is dominated by molecular sky emission (bright features) and background thermal continuum. Note the change of the background levels from order to order. $(b) \mathrm{A}-\mathrm{B}$ echellogram revealing cometary signal: the individual A- and B-frames look like the frame shown in $(a)$. With A-B difference, the sky emission cancels. The comet signal does not cancel because the comet has been moved along the slit. Instead, the B-beam appears negative in the A-B frame. Cometary emission lines are easier to distinguish against the comet continuum in the lower orders. All species indicated are detected simultaneously, which eliminates important systematic effects in the subsequent analysis. Note that the $\mathrm{OH}$ lines are spread over a broader frequency range than the $\mathrm{H}_{2} \mathrm{O}$ lines. Terrestrial atmospheric absorption lines are also seen against the comet continuum. [See the electronic edition of the Journal for a color version of this figure.] 
TABLE 1

OBSERVING LOGS

\begin{tabular}{cccccc}
\hline \hline Comet & UT Date & $\begin{array}{c}R_{h} \\
(\mathrm{AU})\end{array}$ & $\begin{array}{c}\Delta \\
(\mathrm{AU})\end{array}$ & $\begin{array}{c}\Delta \text { dot } \\
\left(\mathrm{km} \mathrm{s}^{-1}\right)\end{array}$ & $\begin{array}{c}T_{\text {int }} \\
\text { (minutes) }\end{array}$ \\
\hline $\mathrm{C} / 2000 \mathrm{WM}_{1} \ldots \ldots \ldots \ldots . . . . .$. & 2001 Nov 25 & 1.321 & 0.357 & -19.1 & 48 \\
$\mathrm{C} / 2004 \mathrm{Q} 2 \ldots \ldots \ldots \ldots \ldots . .$. & 2005 Jan 19 & 1.208 & 0.394 & 11.0 & 8 \\
\hline
\end{tabular}

Note. $-R_{h}, \Delta$, and $\Delta$ dot are, respectively, heliocentric distance, geocentric distance, and radial velocity, with respect to the observing site; $T_{\text {int }}$ is total integration time on source.

or are completely obscured by telluric extinction $\left(\mathrm{P} 3.51^{+}\right.$and $1^{-}$ at $\sim 3447 \mathrm{~cm}^{-1}$ ). Collisional excitation (electrons, neutrals) has not been considered to date.

Quiescent $\mathrm{OH}$ in the coma occupies only low-lying energy levels, so rotational levels higher than $J^{\prime} \sim 4.5$ are not excited efficiently by fluorescence (or collisions) in comets. Instead, they are populated through a fundamentally different mechanismthe photodissociative excitation of the parent $\mathrm{H}_{2} \mathrm{O}$ (Mumma 1982; Crovisier 1989; Bockelée-Morvan \& Crovisier 1989; Mumma et al. 2001). Photolysis of water produces $\mathrm{OH}$ fragments that are both vibrationally and rotationally excited, as demonstrated in multiple laboratory studies (see the review in B04 and Paper II):

$$
h \nu(\mathrm{UV})+\mathrm{H}_{2} \mathrm{O} \rightarrow \mathrm{H}_{2} \mathrm{O}^{*} \rightarrow \mathrm{OH}^{*}+\mathrm{H} .
$$

The quantum state distributions of the dissociation products are governed by the exit channels from the electronically excited dissociative parent state $\left(\mathrm{H}_{2} \mathrm{O}^{*}\right)$, whose excitation in turn depends on the UV photon energy $(h \nu)$ and the initial state population of $\mathrm{H}_{2} \mathrm{O}$.

Rovibrationally excited hydroxyl $\left(\mathrm{OH}^{*}\right)$ can be produced in $X^{2} \Pi$ through several dissociation channels. Photolysis in the first absorption band (FAB) of water $(\lambda>136 \mathrm{~nm})$ dominates because the solar intensity decreases rapidly at higher frequencies (Crovisier 1989), leading almost exclusively to $\mathrm{OH}^{*}\left(X^{2} \Pi\right)$ via the lowest excited electronic state of $\mathrm{H}_{2} \mathrm{O}$. Photolysis in the second absorption band (SAB; primarily by solar Ly $\alpha$ ) also produces mostly $\mathrm{OH}^{*}\left(X^{2} \Pi\right)$. However, other end-state products [e.g., electronically excited $\mathrm{OH}^{*}\left(A^{2} \Sigma^{+}\right)$] are also produced with significant branching ratios (Harich et al. 2000).

The rovibrationally excited (or "rotationally hot") states leading to infrared emission in the (1-0) band can be produced directly by $\mathrm{H}_{2} \mathrm{O}$ photolysis or indirectly via decay from dissociatively excited $\mathrm{OH}$ levels of higher energy. From $X^{2} \Pi$, IR radiative decay $v^{\prime}=1$ to $v^{\prime \prime}=0$ occurs within $\sim 10 \mathrm{~ms}$; this type of emission is called "prompt," as the dissociation fragment emits promptly after its production. After decaying to $v^{\prime \prime}=0$, collisions rapidly quench the high rotational states, bringing the quiescent $\mathrm{OH}$ into equilibrium at a low rotational temperature and preventing subsequent fluorescent excitation of high- $J$ levels. The $\mathrm{OH}$ transitions reported here are examples of $\mathrm{OH}$ vibrational prompt emission (PE). Previous studies of OH PE were reviewed in B04.

\section{SPATIAL DISTRIBUTIONS OF INFRARED $\mathrm{H}_{2} \mathrm{O}$ AND OH EMISSION}

The spatial profile of the OH PE intensity does not provide information about the distribution of quiescent $\mathrm{OH}$ in the coma. Brooke et al. (1996) noted that the two P6.5 $2^{+}$and $2^{-}(1-0)$ band lines of OH detected in C/1996 B2 (Hyakutake) were sharply peaked at the nucleus, which is characteristic of PE, while two (2-1) band lines of lower rotational excitation (P3.5 $1^{+}$and $1^{-}$) had spatial distributions with both prompt and fluorescent components. (Unlike PE, the spatial profile of fluorescent $\mathrm{OH}$ is much flatter and in most cases does not peak at the nucleus [e.g., Weaver et al. 1999].) In B04, we reported the first direct comparison of simultaneously measured high- $J \mathrm{OH}$ (via the $N^{\prime}=11$ quadruplet near $3046 \mathrm{~cm}^{-1}$ ) and $\mathrm{H}_{2} \mathrm{O}$ (via hot-band emission near $2.9 \mu \mathrm{m}$ ) in comets C/1999 H1 (Lee) and C/2001 A2 (LINEAR), and we demonstrated that the spatial profile of $\mathrm{OH}^{*}$ tracks closely that of $\mathrm{H}_{2} \mathrm{O}$, as expected for PE.

In this section we compare directly the spatial distributions of $\mathrm{OH}^{*}$ and $\mathrm{H}_{2} \mathrm{O}$ intensities in $\mathrm{C} / 2000 \mathrm{WM}_{1}$ and $\mathrm{C} / 2004 \mathrm{Q} 2$. We first demonstrate that in spite of possible contributions from fluorescence, the intensity distribution of the $\mathrm{P} 4.51^{+}, 1^{-}$doublet in order $26\left(\sim 3407 \mathrm{~cm}^{-1}\right)$ implies a significant PE component. We also show that although the general notion that the OH PE tracks the parent is valid, comet $\mathrm{C} / 2004 \mathrm{Q} 2$ presents a special case in which the apparent spatial profiles of $\mathrm{OH}^{*}$ and $\mathrm{H}_{2} \mathrm{O}$ differ along lines of sight passing the innermost region to the nucleus.

\section{1. $\mathrm{C} / 2000 \mathrm{WM}_{1}$ (LINEAR)}

The spatial profiles of $\mathrm{H}_{2} \mathrm{O}$ and $\mathrm{OH}^{*}$ in $\mathrm{C} / 2000 \mathrm{WM}_{1}$ are compared in Figure 4. We summed (column by column) many $\mathrm{H}_{2} \mathrm{O}$ lines near $2.9 \mu \mathrm{m}$ (Fig. $2 a$; order 26), forming the water profile. $\mathrm{OH}$ profiles were formed by summing (order $23 ; N^{\prime}=11$ ) the signal over the four lines from the (1-0) band quadruplet near $3046 \mathrm{~cm}^{-1}\left(\mathrm{P} 11.52^{+}, 2^{-}\right.$; and P12.5 $\left.1^{+}, 1^{-}\right)$, and by summing (order 26; $N^{\prime}=3$ ) two lines near $3407 \mathrm{~cm}^{-1}\left(\mathrm{P} 4.51^{+}, 1^{-}\right)$. The $\mathrm{OH}$ profiles are normalized to the $\mathrm{H}_{2} \mathrm{O}$ profile by summing over several spatial pixels on the wings of these profiles, as indicated in Figure 4, and scaling to the corresponding measurement for $\mathrm{H}_{2} \mathrm{O}$. An almost identical appearance is accomplished if the $\mathrm{OH}$ profiles are scaled according to the mean signal in their central pixels (see Fig. 20 of Bonev 2005).

The parent-like profile of the $\mathrm{OH}$ quadruplet in order 23 confirms the results of B04, which were based on observations of C/1999 H1 (Lee) and C/2001 A2 (LINEAR). The four lines between 3043 and $3048 \mathrm{~cm}^{-1}$ sample sufficiently high rotational levels $\left(J^{\prime}=10.5,11.5\right)$ to be solely attributed to PE. The congruence between the profiles of $\mathrm{H}_{2} \mathrm{O}$ and of the $\mathrm{P} 4.51^{+}$and $1^{-} \mathrm{OH}$ doublet implies that this emission also is dominated by a PE component, despite its relatively low rotational excitation $\left(J^{\prime}=3.5\right)$.

\subsection{C/2004 Q2 (Machholz)}

The spatial profiles of $\mathrm{OH}^{*}$ and $\mathrm{H}_{2} \mathrm{O}$ differ in comet $\mathrm{C} / 2004$ Q2. The profile of $\mathrm{H}_{2} \mathrm{O}$ emission (order 26) is compared with that of $\mathrm{OH}$ measured in order $26\left(\mathrm{P} 4.51^{+}, 1^{-}\right), 24$ ( $\mathrm{P} 9.51^{+}, 1^{-}$; P9.5 $\left.2^{+}, 2^{-}\right)$, and $23\left(\mathrm{P} 11.52^{+}, 2^{-} ; \mathrm{P} 12.51^{+}, 1^{-}\right)$in Figures 5,6 , and 7 , respectively. (OH emissions from other orders are not strong enough to construct reliable spatial profiles.) The $\mathrm{OH}$ and $\mathrm{H}_{2} \mathrm{O}$ profiles are internormalized, as was done for $\mathrm{C} / 2000 \mathrm{WM}_{1}$. Figures 5-7 suggest that some $\mathrm{OH}$ intensity is "missing" from the center of the spatial distributions, but elsewhere the intensity from hydroxyl tracks the water intensity, as expected for PE. The discrepancy between the $\mathrm{H}_{2} \mathrm{O}$ and $\mathrm{OH}^{*}$ profiles is larger for hydroxyl lines of higher rotational excitation $\left(N^{\prime}=8,9\right.$, and 11; see Table 2$)$. 


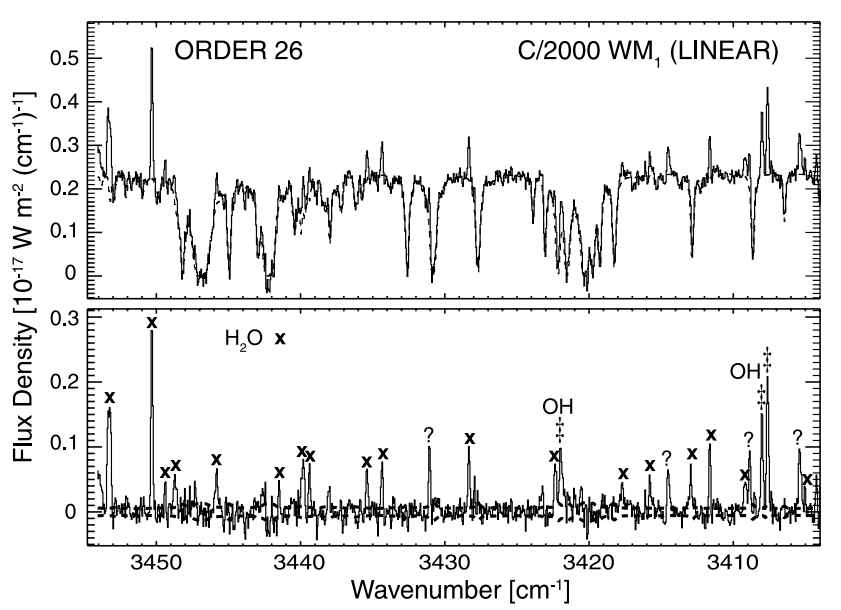

FIG. $2 a$

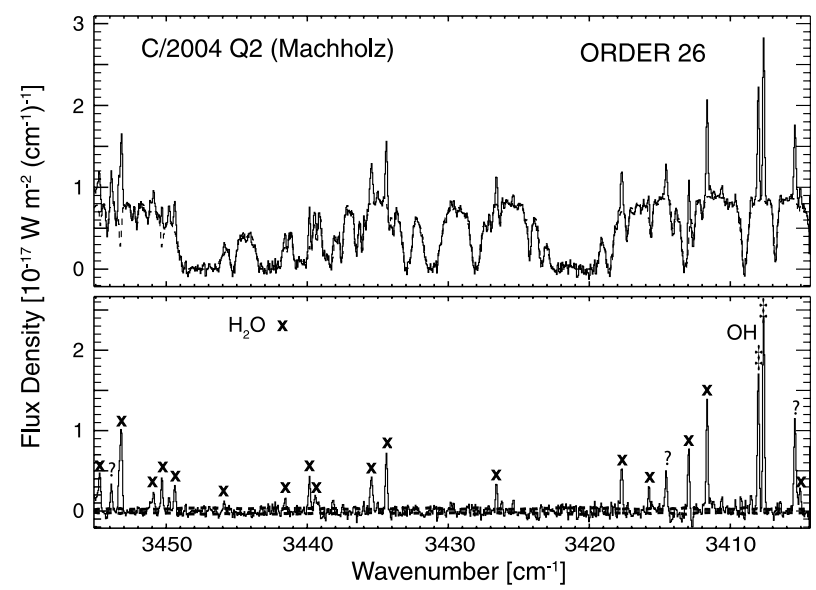

FIG. $2 b$

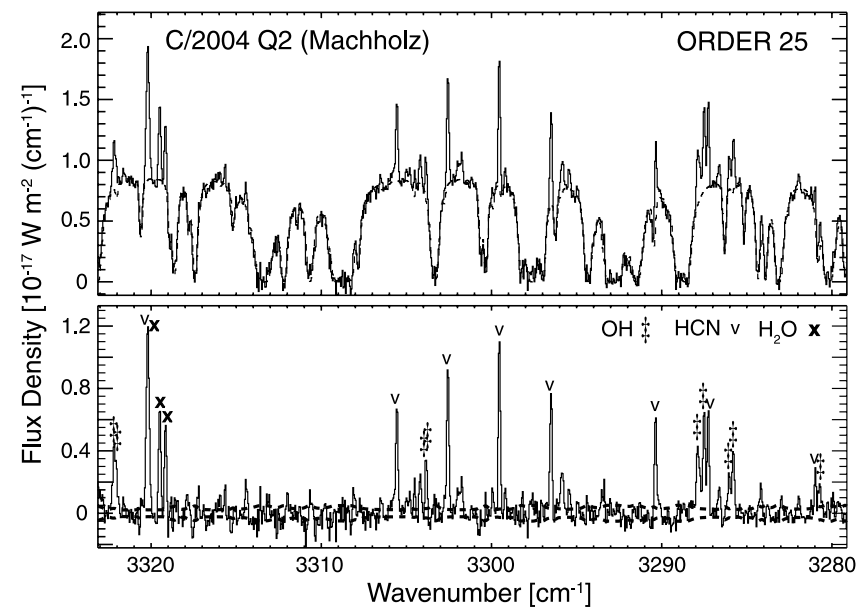

FIG. $2 c$

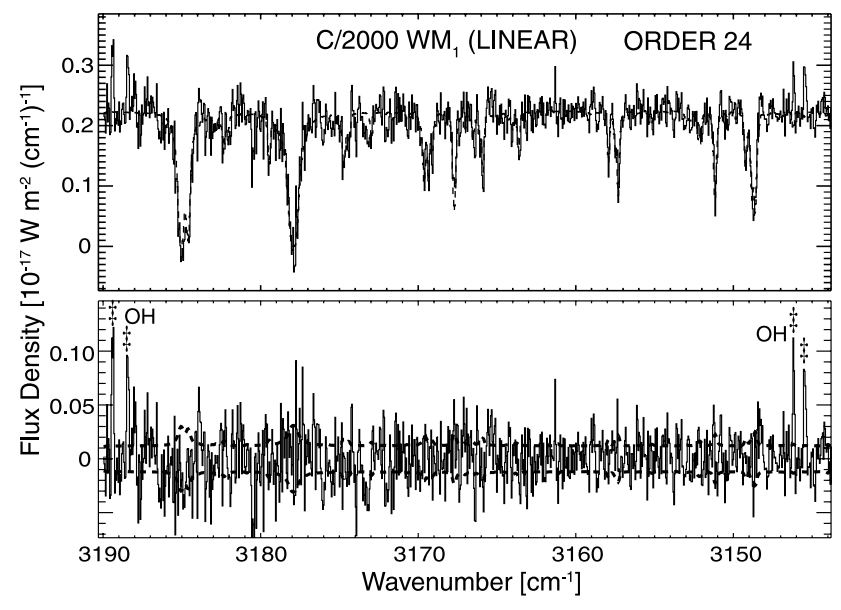

FIG. $2 d$

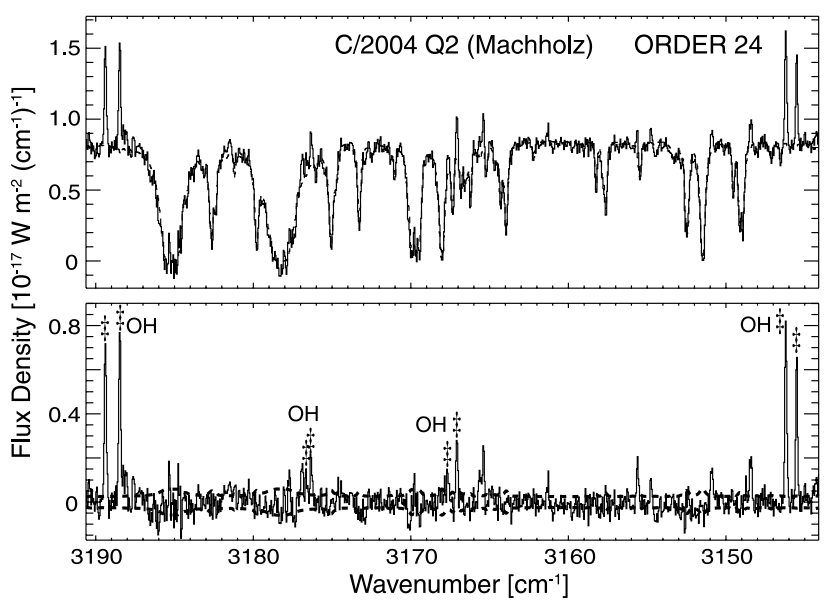

FIG. $2 e$

FIG. 2.-Emission from C/2000 $\mathrm{WM}_{1}$ and C/2004 Q2: spectral extracts from orders 26, 25 (C/2004 Q2 only), 24,23 , and 21 in the KL2 NIRSPEC setting. Each

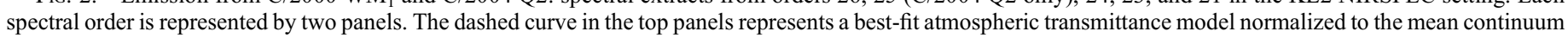
intensity of the comet data. The bottom panels show residual spectra after modeling out the telluric absorption. The dashed lines outline the $1 \sigma$ photon noise envelope.

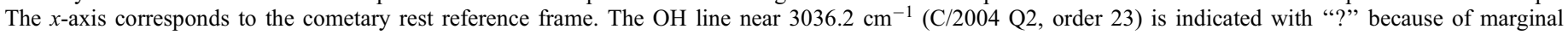

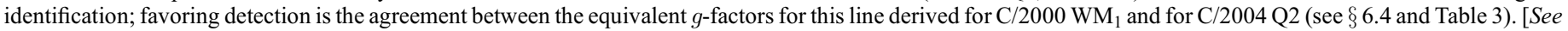
the electronic edition of the Journal for a color version of this figure.] 


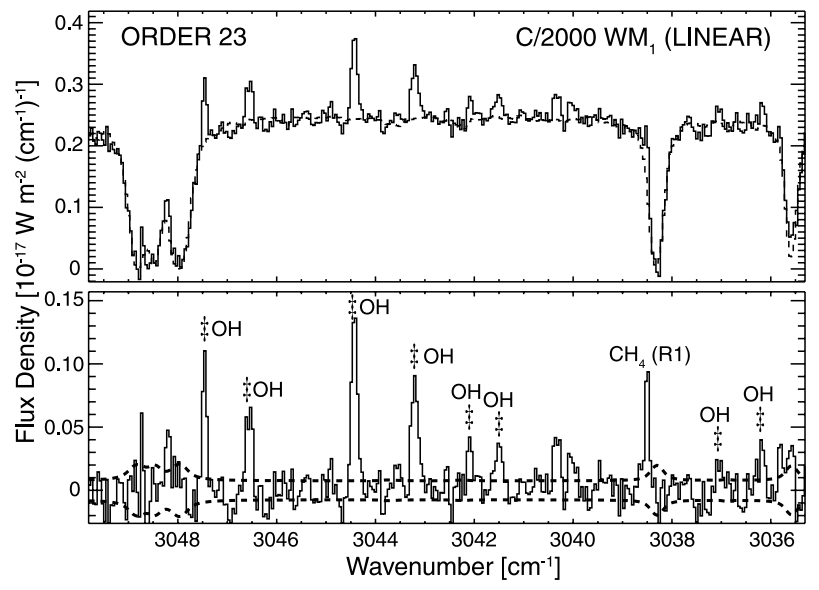

FIG. $2 f$

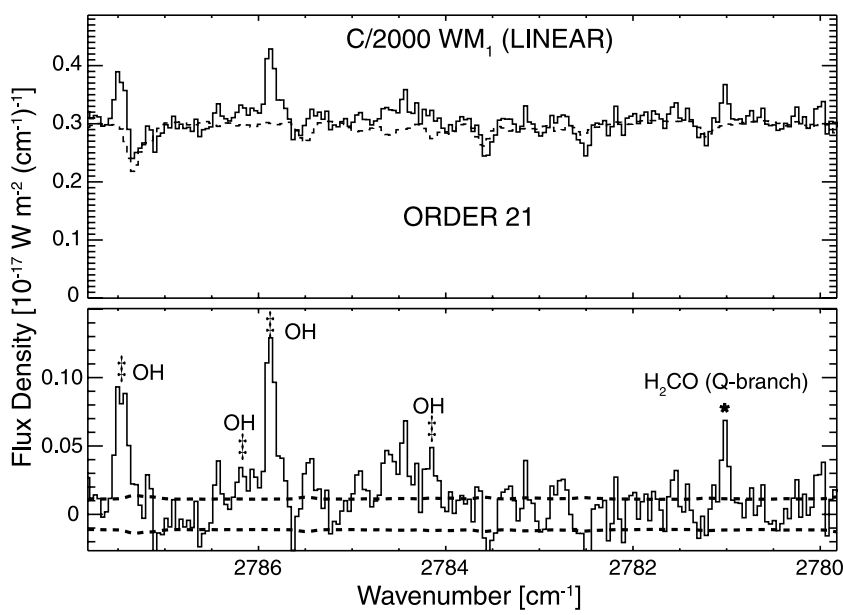

FIG. $2 h$

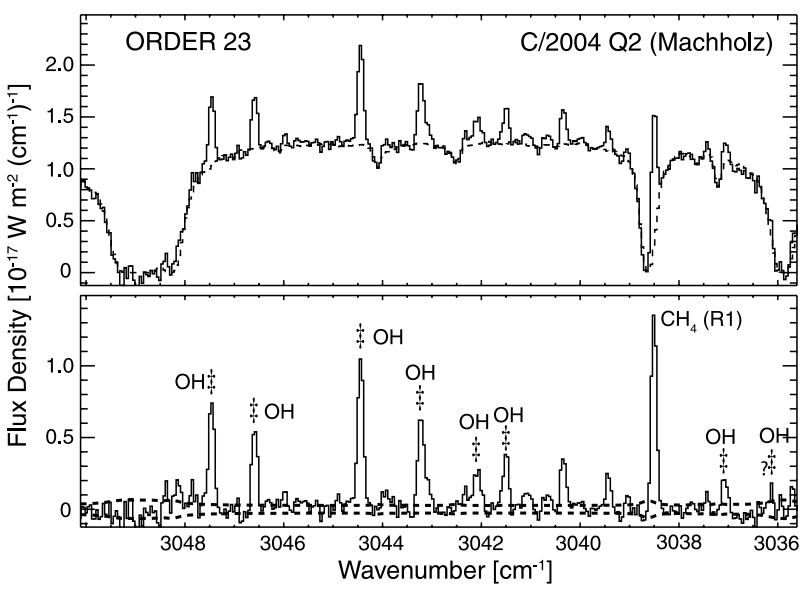

FIG. $2 g$

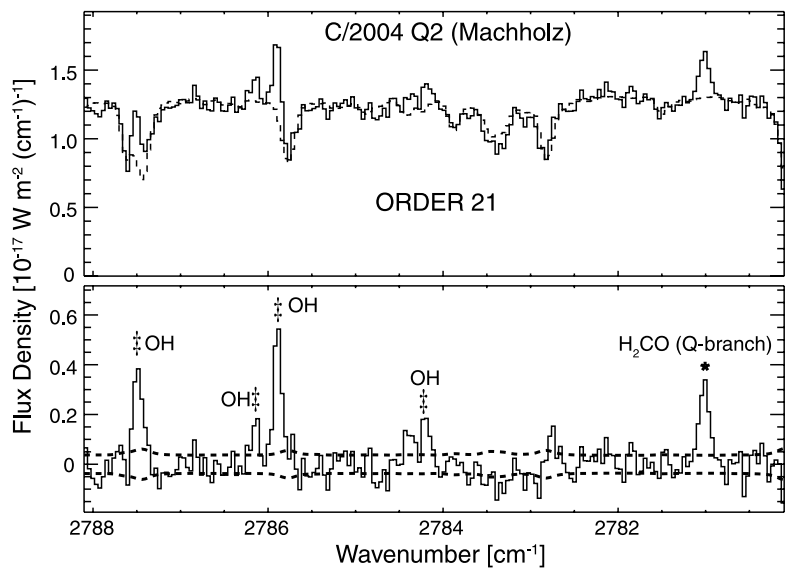

FIG. $2 i$

FIG. 2.-Continued
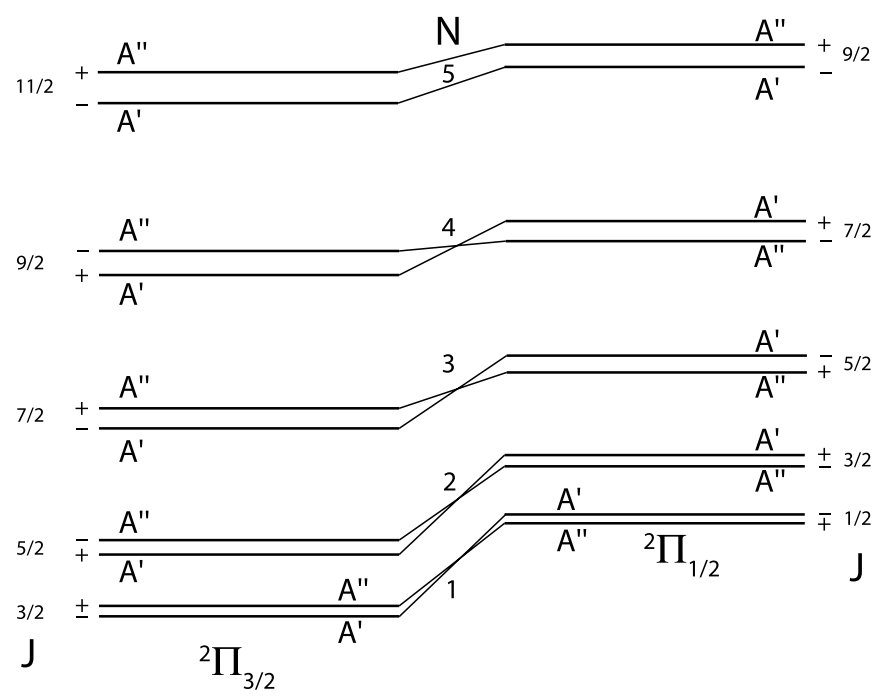

FIG. 3.-Schematic representation (not to scale) of rotational levels in the ground electronic state of $\mathrm{OH}\left(X^{2} \Pi\right)$ (see text for details). Levels with the same value of $N$ from the ${ }^{2} \Pi_{3 / 2}$ and ${ }^{2} \Pi_{1 / 2}$ "ladders" are connected by sloping lines, as done in Herzberg (1988). [See the electronic edition of the Journal for a color version of this figure.]
It should be emphasized that the $\mathrm{OH}^{*}$ and $\mathrm{H}_{2} \mathrm{O}$ profiles are still correlated, although not as tightly as for $\mathrm{C} / 2000 \mathrm{WM}_{1}$. The apparent difference between the spatial distributions of $\mathrm{H}_{2} \mathrm{O}$ and $\mathrm{OH}^{*}$ would be reconciled if $\mathrm{OH}$ is underproduced in the innermost region of the coma, represented by the central regions of the profiles. Optical depth effects in the solar UV radiation responsible for the photodissociation of water are one plausible explanation for this effect (see Appendix A).

\section{EQUIVALENT $g$-FACTORS FOR OH INFRARED PROMPT EMISSION IN C/2000 $\mathrm{WM}_{1}$ AND C/2004 Q2}

\subsection{Quantitative $\mathrm{OH}$ Emission Efficiencies}

The main idea in the extraction of equivalent $g$-factors (emission efficiencies) for $\mathrm{OH} \mathrm{PE}$ is that the method already established for analysis of $\mathrm{H}_{2} \mathrm{O}$ nonresonant fluorescence is used initially as a "calibrator" for the $\mathrm{PE}$ efficiencies. The $\mathrm{H}_{2} \mathrm{O}$ production rate, $Q$, is measured directly from nonresonant fluorescence lines detected within the same instrument setting as (i.e., simultaneously with) $\mathrm{OH}$. For each $\mathrm{OH}$ line, the $\mathrm{H}_{2} \mathrm{O}$ production rate is also derived from the measured flux in that line (also corrected for terrestrial atmospheric transmittance), $F\left(\mathrm{OH}^{*}\right)$, as prescribed in $\S 6.3$. The OH PE $g$-factor is treated as a free parameter and is adjusted until the water production rate deduced from the $\mathrm{OH}$ 
TABLE 2

OH Lines Analyzed in C/2000 $\mathrm{WM}_{1}$ and C/2004 Q2

\begin{tabular}{|c|c|c|c|c|c|c|c|c|}
\hline Order & Band & Line ID & $N^{\prime}$ & $\begin{array}{c}\nu_{0} \\
\left(\mathrm{~cm}^{-1}\right)\end{array}$ & $F_{1}\left(\mathrm{WM}_{1}\right)$ & $\sigma_{F_{1}}$ & $F_{2}(\mathrm{Q} 2)$ & $\sigma_{F_{2}}$ \\
\hline \multirow[t]{2}{*}{$26 \ldots \ldots \ldots \ldots$} & $1-0$ & P4.5 $1^{+}$ & 3 & 3407.9890 & $2.63 \mathrm{E}-19$ & $6.76 \mathrm{E}-21$ & $3.05 \mathrm{E}-18$ & $3.04 \mathrm{E}-20$ \\
\hline & $1-0$ & P4.5 $1^{-}$ & 3 & 3407.6069 & $3.55 \mathrm{E}-19$ & $7.50 \mathrm{E}-21$ & $4.16 \mathrm{E}-18$ & $3.03 \mathrm{E}-20$ \\
\hline \multirow[t]{9}{*}{$25 \ldots \ldots \ldots \ldots \ldots \ldots$} & $1-0$ & P6.5 $2^{-}$ & 6 & 3287.8759 & $\ldots$ & $\ldots$ & $1.18 \mathrm{E}-18$ & $4.94 \mathrm{E}-20$ \\
\hline & $1-0$ & P $6.52^{+}$ & 6 & 3287.4742 & $\ldots$ & $\ldots$ & $1.33 \mathrm{E}-18$ & $3.66 \mathrm{E}-20$ \\
\hline & $1-0$ & P7.5 $1^{-}$ & 6 & 3280.7410 & $\ldots$ & $\ldots$ & $1.11 \mathrm{E}-18$ & $1.69 \mathrm{E}-19$ \\
\hline & $2-1$ & P $2.51^{+}$ & 1 & 3322.1244 & $\ldots$ & $\ldots$ & $1.52 \mathrm{E}-18$ & $5.41 \mathrm{E}-20$ \\
\hline & $2-1$ & P2.5 $1^{-}$ & 1 & 3322.0115 & $\ldots$ & $\ldots$ & $\ldots$ & $\ldots$ \\
\hline & $2-1$ & P2.5 $2^{+}$ & 2 & 3303.8051 & $\ldots$ & $\ldots$ & $8.47 \mathrm{E}-19$ & $5.20 \mathrm{E}-20$ \\
\hline & $2-1$ & P2.5 $2^{-}$ & 2 & 3303.8051 & $\ldots$ & $\ldots$ & $\ldots$ & $\ldots$ \\
\hline & $2-1$ & P3.5 $1^{-}$ & 2 & 3286.0109 & $\ldots$ & $\ldots$ & $4.98 \mathrm{E}-19$ & $4.14 \mathrm{E}-20$ \\
\hline & $2-1$ & P3.5 $1^{+}$ & 2 & 3285.7591 & $\ldots$ & $\ldots$ & $7.95 \mathrm{E}-19$ & $3.81 \mathrm{E}-20$ \\
\hline \multirow[t]{8}{*}{$24 \ldots \ldots \ldots \ldots$} & $1-0$ & P9.5 $1^{-}$ & 8 & 3189.3929 & $1.81 \mathrm{E}-19$ & $1.17 \mathrm{E}-20$ & $1.19 \mathrm{E}-18$ & $2.86 \mathrm{E}-20$ \\
\hline & $1-0$ & P9.5 $1^{+}$ & 8 & 3188.4785 & $1.58 \mathrm{E}-19$ & $1.18 \mathrm{E}-20$ & $1.36 \mathrm{E}-18$ & $3.16 \mathrm{E}-20$ \\
\hline & $1-0$ & P9.5 $2^{+}$ & 9 & 3146.1824 & $1.86 \mathrm{E}-19$ & $1.86 \mathrm{E}-20$ & $1.23 \mathrm{E}-18$ & $2.82 \mathrm{E}-20$ \\
\hline & $1-0$ & P9.5 $2^{-}$ & 9 & 3145.4909 & $1.48 \mathrm{E}-19$ & $1.40 \mathrm{E}-20$ & $9.41 \mathrm{E}-19$ & $2.98 \mathrm{E}-20$ \\
\hline & $2-1$ & P5.5 $2^{+}$ & 5 & 3176.5877 & $\ldots$ & $1.48 \mathrm{E}-20$ & $2.92 \mathrm{E}-19$ & $5.17 \mathrm{E}-20$ \\
\hline & $2-1$ & P5.5 $2^{-}$ & 5 & 3176.3171 & $\ldots$ & $1.44 \mathrm{E}-20$ & $4.10 \mathrm{E}-19$ & $4.26 \mathrm{E}-20$ \\
\hline & $2-1$ & P6.5 $1^{+}$ & 5 & 3167.6663 & $\ldots$ & $9.41 \mathrm{E}-20$ & $2.56 \mathrm{E}-19$ & $5.58 \mathrm{E}-20$ \\
\hline & $2-1$ & P6.5 1- & 5 & 3167.0698 & $\ldots$ & $1.84 \mathrm{E}-20$ & $4.92 \mathrm{E}-19$ & $3.77 \mathrm{E}-20$ \\
\hline \multirow[t]{8}{*}{$23 \ldots \ldots \ldots \ldots \ldots$} & $1-0$ & $\mathrm{P} 11.52^{+}$ & 11 & 3047.4576 & $1.43 \mathrm{E}-19$ & $1.16 \mathrm{E}-20$ & $1.33 \mathrm{E}-18$ & $3.99 \mathrm{E}-20$ \\
\hline & $1-0$ & $\mathrm{P} 11.52^{-}$ & 11 & 3046.5508 & $1.09 \mathrm{E}-19$ & $8.17 \mathrm{E}-21$ & $8.48 \mathrm{E}-19$ & $3.06 \mathrm{E}-20$ \\
\hline & $1-0$ & P12.5 $1^{+}$ & 11 & 3044.4280 & $2.06 \mathrm{E}-19$ & $7.74 \mathrm{E}-21$ & $1.58 \mathrm{E}-18$ & $2.83 \mathrm{E}-20$ \\
\hline & $1-0$ & $\mathrm{P} 12.51^{-}$ & 11 & 3043.2137 & $1.51 \mathrm{E}-19$ & $7.94 \mathrm{E}-21$ & $1.03 \mathrm{E}-18$ & $2.75 \mathrm{E}-20$ \\
\hline & $2-1$ & P8.5 2- & 8 & 3042.0748 & $4.96 \mathrm{E}-20$ & $8.08 \mathrm{E}-21$ & $4.47 \mathrm{E}-19$ & $2.73 \mathrm{E}-20$ \\
\hline & $2-1$ & P8.5 $2^{+}$ & 8 & 3041.5069 & $6.03 \mathrm{E}-20$ & $7.67 \mathrm{E}-21$ & $6.16 \mathrm{E}-19$ & $2.99 \mathrm{E}-20$ \\
\hline & $2-1$ & P9.5 $1^{-}$ & 8 & 3037.0490 & $3.36 \mathrm{E}-20$ & $8.54 \mathrm{E}-21$ & $3.59 \mathrm{E}-19$ & $4.22 \mathrm{E}-20$ \\
\hline & $2-1$ & P9.5 $1^{+}$ & 8 & 3036.1708 & $4.54 \mathrm{E}-20$ & $9.31 \mathrm{E}-21$ & $4.17 \mathrm{E}-19$ & $1.44 \mathrm{E}-19$ \\
\hline \multirow[t]{4}{*}{$21 \ldots \ldots \ldots \ldots \ldots \ldots$} & $1-0$ & $\mathrm{P} 16.52^{-}$ & 16 & 2787.4646 & $1.53 \mathrm{E}-19$ & $1.15 \mathrm{E}-20$ & $1.05 \mathrm{E}-18$ & $1.06 \mathrm{E}-19$ \\
\hline & $1-0$ & $\mathrm{P} 16.52^{+}$ & 16 & 2786.1482 & $5.60 \mathrm{E}-20$ & $1.04 \mathrm{E}-20$ & $2.12 \mathrm{E}-19$ & $3.51 \mathrm{E}-20$ \\
\hline & $1-0$ & P17.5 $1^{-}$ & 16 & 2785.8729 & $1.71 \mathrm{E}-19$ & $1.04 \mathrm{E}-20$ & $7.20 \mathrm{E}-19$ & $4.89 \mathrm{E}-20$ \\
\hline & $1-0$ & $\mathrm{P} 17.51^{+}$ & 16 & 2784.1880 & $6.49 \mathrm{E}-20$ & $1.17 \mathrm{E}-20$ & $2.39 \mathrm{E}-19$ & $3.72 \mathrm{E}-20$ \\
\hline
\end{tabular}

Notes.- OH lines analyzed quantitatively are given for each NIRSPEC order of the KL2 setting. The nomenclature of transitions is explained in the main text $\left(\S 3\right.$ ). Lines with common $N^{\prime}$ (rotational quantum number apart from spin for the upper state) belong to the same "quadruplet"; $\nu_{0}$ is the rest frequency. $F_{1}\left(\mathrm{WM}_{1}\right)$ and $F_{2}(\mathrm{Q} 2)$ are transmittance-corrected line fluxes $\left(\mathrm{W} \mathrm{m}^{-2}\right)$ for the nucleus-centered region $\left(0\right.$ " $\left.43 \times 11^{\prime \prime} 78\right)$; their errors $\left(\sigma_{F_{1}}\right.$ and $\sigma_{F_{2}}$ ) are estimates of the local photon noise for the corresponding frequencies, which is larger at the presence of sky emission lines in the "raw" data (e.g., Fig. 1a). Order 25 contains lines from multiple species; it is the most problematic in terms of spectral overlaps and is analyzed only in $\mathrm{C} / 2004 \mathrm{Q} 2$, the brighter of the two comets. The P2.5 $1^{+}$and $1^{-}$lines and the P2.5 $2^{+}$and $2^{-}$lines are blended, so only their summed fluxes are reported. Order 24 lines from the (2-1) band are not detected in $\mathrm{C} / 2000 \mathrm{WM}_{1}$, but $3 \sigma$ upper limits for their equivalent $g$-factors may be calculated based on the local photon noise.

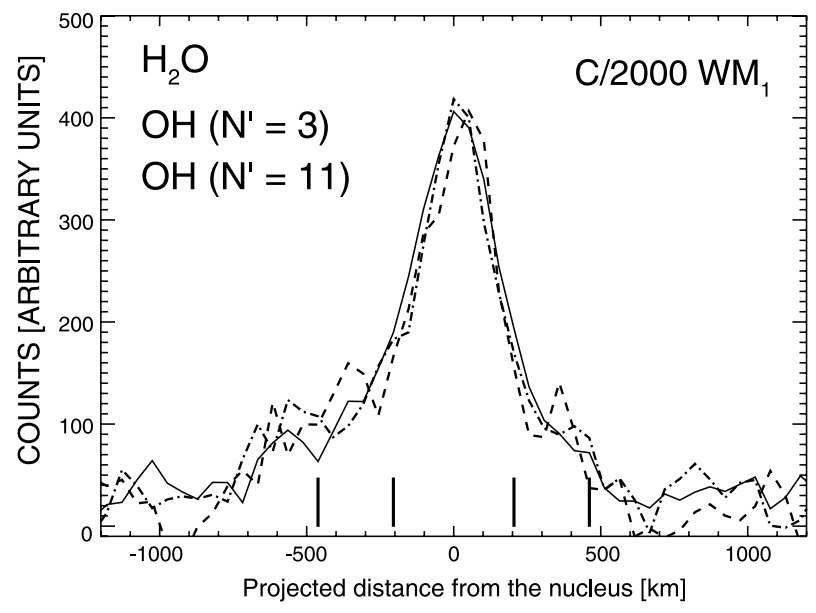

FIG. 4.- Spatial profiles of $\mathrm{H}_{2} \mathrm{O}$ (solid line) and $\mathrm{OH}$ emission in $\mathrm{C} / 2000 \mathrm{WM}_{1}$. The $\mathrm{OH}$ profiles are normalized to the $\mathrm{H}_{2} \mathrm{O}$ profile by summing over the signal within the spatial ranges indicated by vertical lines and scaling to the corresponding measurement for $\mathrm{H}_{2} \mathrm{O}$. The slit orientation varied within $124^{\circ}-95^{\circ}$ east of north (in rotator stationary mode), with the sunward direction approximately west. [See the electronic edition of the Journal for a color version of this figure.]

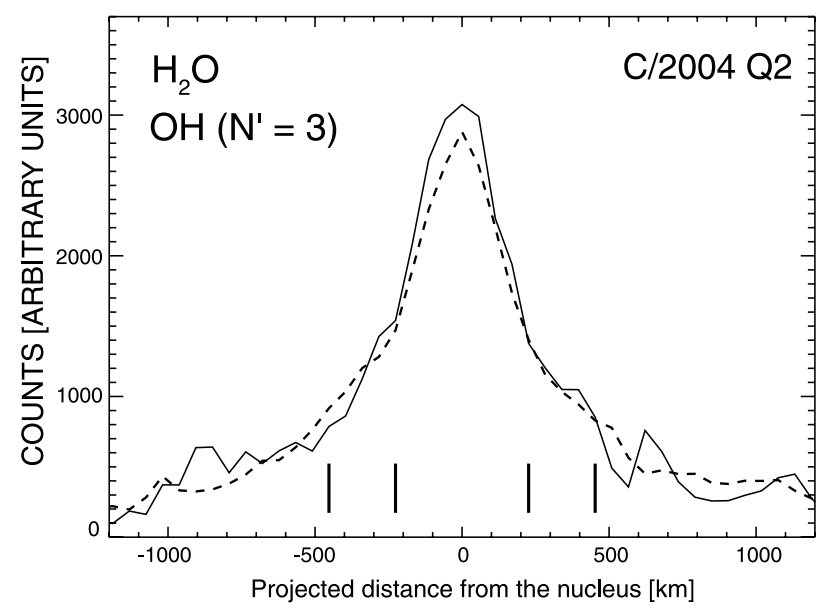

FIG. 5.- Spatial profiles of $\mathrm{H}_{2} \mathrm{O}$ (solid line) and $\mathrm{OH}\left(N^{\prime}=3\right)$ emission in $\mathrm{C} / 2004 \mathrm{Q} 2$ (the $\mathrm{OH}$ profiles are normalized the same way as in Fig. 4). The slit was oriented approximately south-north, with the sunward direction perpendicular to it. [See the electronic edition of the Journal for a color version of this figure.] 


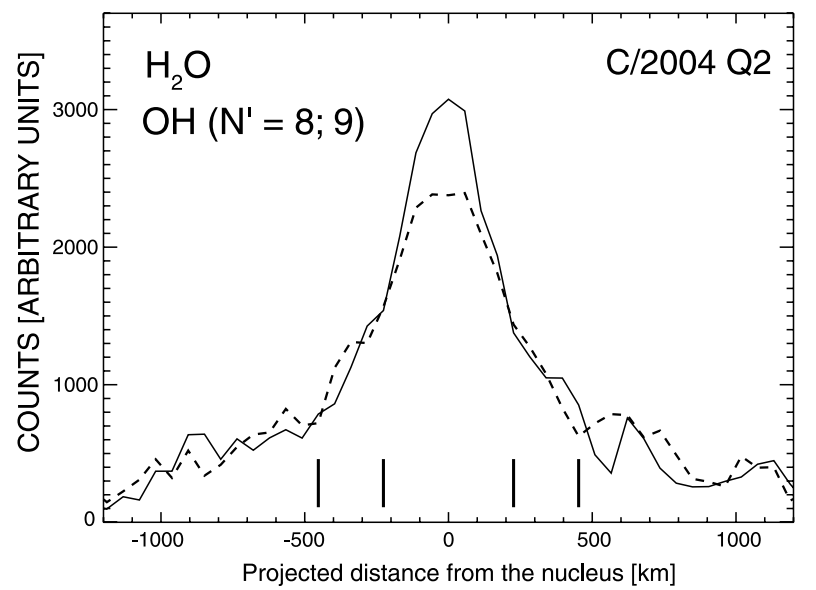

FIG. 6.- Spatial profiles of $\mathrm{H}_{2} \mathrm{O}$ (solid line) and $\mathrm{OH}\left(N^{\prime}=8\right.$ and 9) emission in $\mathrm{C} / 2004 \mathrm{Q} 2$ (the $\mathrm{OH}$ profiles are normalized the same way as in Fig. 4). [See the electronic edition of the Journal for a color version of this figure.]

data $\left(Q^{*}\right)$ equals the production rate directly obtained from water lines $(Q)$. This approach was suggested by Mumma et al. (2001) and was applied in B04. Given the simultaneity of $\mathrm{OH}$ and $\mathrm{H}_{2} \mathrm{O}$ observations, the direct water measurements provide a calibrator for the PE efficiency. The $g$-factors derived from $\mathrm{H}_{2} \mathrm{O}$ and $\mathrm{OH}$ infrared spectra can then be used to obtain $\mathrm{H}_{2} \mathrm{O}$ production rates in other comets (especially in cases when $\mathrm{OH}$ and $\mathrm{H}_{2} \mathrm{O}$ cannot be sampled simultaneously) and also to test predictions of future modeling efforts that aim to describe the distribution of rovibrationally excited $\mathrm{OH}$ states produced by water photolysis (the latter application is discussed in Bonev [2005] and in Paper II).

\subsection{Water Production Rates from $\mathrm{H}_{2} \mathrm{O}$ Nonresonant Fluorescence near $2.9 \mu \mathrm{m}$}

$\mathrm{H}_{2} \mathrm{O}$ production rates were derived directly from analysis of hot-band fluorescent emission near $2.9 \mu \mathrm{m}$ (Figs. $2 a$ and $2 b$ ). The complete derivation of rotational temperatures, ortho-para ratios, spin temperatures, and production rates for $\mathrm{H}_{2} \mathrm{O}$ in $\mathrm{C} / 2000$ $\mathrm{WM}_{1}$ and $\mathrm{C} / 2004 \mathrm{Q} 2$ is given in Bonev (2005), including a description of the $\mathrm{H}_{2} \mathrm{O}$ fluorescence models (see also Dello Russo et al. 2004, 2005) and uncertainties in the retrieved parameters. The directly measured $\mathrm{H}_{2} \mathrm{O}$ production rate can be obtained from this expression:

$$
Q=P\left\langle\frac{F\left(\mathrm{H}_{2} \mathrm{O}\right)}{g_{\mathrm{fl}}(h c \nu)}\right\rangle \mathrm{GF},
$$

where $\left\langle F\left(\mathrm{H}_{2} \mathrm{O}\right) / g_{\mathrm{fl}}(h c \nu)\right\rangle$ is the averaged (over line-by-line measurements) ratio between transmittance-corrected $\mathrm{H}_{2} \mathrm{O}$ line flux $\left(\mathrm{W} \mathrm{m}^{-2}\right)$ and fluorescence efficiency $\left(\mathrm{W}\left[\mathrm{H}_{2} \mathrm{O} \text { molecule }\right]^{-1}\right)$; the latter is equal to the product of the fluorescent emission $g$-factor $g_{\mathrm{fl}}\left(\mathrm{H}_{2} \mathrm{O}\right.$ photons s$\left.{ }^{-1}\left[\mathrm{H}_{2} \mathrm{O} \text { molecule }\right]^{-1}\right)$ and the energy $h c \nu(J)$ of a photon with frequency $\nu$. The parameter $P$ depends on the geocentric distance, the photodissociation lifetime of $\mathrm{H}_{2} \mathrm{O}$, and the fraction of the $\mathrm{H}_{2} \mathrm{O}$ molecules expected in the sampled region of the coma. For detailed discussions of equation (1), see, for example, Dello Russo et al. (2004) or Gibb et al. (2003) and references therein.

Our flux measurements of individual $\mathrm{H}_{2} \mathrm{O}$ lines, $F\left(\mathrm{H}_{2} \mathrm{O}\right)$, are extracted over the nucleus-centered region, i.e., 3 pixels in the spectral dimension (corresponding to the entrance slit width) by 9 spatial pixels $\left(0.43 \times 11^{\prime \prime} 78\right)$ centered on the nucleus. The quantity GF is a growth factor that accounts for loss of flux near the nucleus, due mainly to atmospheric seeing effects (thus, GF exceeds unity; see

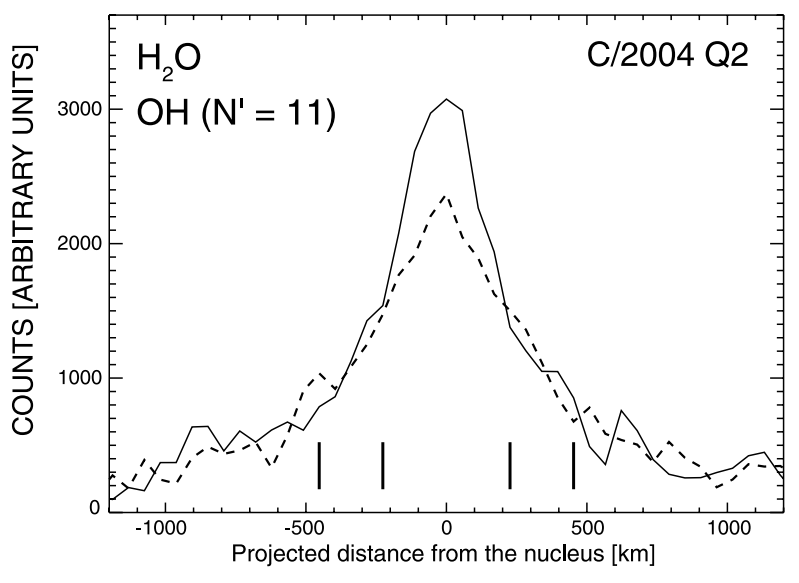

FIg. 7.- Spatial profiles of $\mathrm{H}_{2} \mathrm{O}$ (solid line) and $\mathrm{OH}\left(N^{\prime}=11\right)$ emission in $\mathrm{C} / 2004 \mathrm{Q} 2$ (the $\mathrm{OH}$ profiles are normalized the same way as in Fig. 4). [See the electronic edition of the Journal for a color version of this figure.]

Dello Russo et al. 1998). The calculation of this parameter is described in Dello Russo et al. $(2004,2005)$; an example of growth factor retrieval is presented in Appendix B. The approach to scaling nucleus-centered flux measurements by the appropriate growth factor correction (based on the spatial profile of emission summed over multiple lines) provides higher signal-to-noise ratios $(\mathrm{S} / \mathrm{N})$ possible for line-by-line production rates (compared with measuring the GF for each line separately). This method has been used for comets with weak to moderate gas productivity (e.g., Dello Russo et al. 2005; DiSanti et al. 2006).

The directly measured $\mathrm{H}_{2} \mathrm{O}$ production rates for $\mathrm{C} / 2000 \mathrm{WM}_{1}$ and $\mathrm{C} / 2004 \mathrm{Q} 2$ are, respectively, $(2.1 \pm 0.1) \times 10^{28}$ and $(2.6 \pm$ $0.1) \times 10^{29}$ molecules s $^{-1}$. For comparison, we also provide the nucleus-centered production rates, obtained without a growth factor correction: $(1.4 \pm 0.1) \times 10^{28}\left(\mathrm{C} / 2000 \mathrm{WM}_{1}\right)$ and $(1.4 \pm$ $0.1) \times 10^{29}(\mathrm{C} / 2004 \mathrm{Q} 2)$ molecules $\mathrm{s}^{-1}$.

\subsection{Water Production Rates from Individual $\mathrm{OH}$ Line Fluxes and Equivalent g-Factors}

The $\mathrm{H}_{2} \mathrm{O}$ production rate may be calculated from individual $\mathrm{OH}$ PE line flux $F\left(\mathrm{OH}^{*}\right)\left(\mathrm{W} \mathrm{m}^{-2}\right)$ and an equivalent $g$-factor $\left(\mathrm{OH}\right.$ photons s $\left.{ }^{-1}\left[\mathrm{H}_{2} \mathrm{O} \text { molecule }\right]^{-1}\right)$ via an expression analogical to equation (1),

$$
Q^{*}=P\left[\frac{F\left(\mathrm{OH}^{*}\right)}{g(h c \nu)^{*}}\right] \mathrm{GF}^{*} .
$$

The unit of the equivalent $g$-factor implies that, by definition, this quantity connects the observed $\mathrm{OH} \mathrm{PE}$ line flux to the total production of $\mathrm{H}_{2} \mathrm{O}$, not of $\mathrm{OH}$ (Mumma et al. 2001). All transmittancecorrected $\mathrm{OH}$ line fluxes, $F\left(\mathrm{OH}^{*}\right)$, are reported in Table 2 and are extracted from the nucleus-centered region; $(h c \nu)^{*}$ denotes the energy of $\mathrm{OH}$ photon with frequency $\nu$; and $\mathrm{GF}^{*}$ is the growth factor correction for nucleus-centered $\mathrm{OH}$ emission line fluxes. In addition to observing-related effects such as atmospheric seeing, it also accounts for the difference between the $\mathrm{OH}^{*}$ and $\mathrm{H}_{2} \mathrm{O}$ spatial intensity profiles observed in C/2004 Q2 (Appendix B).

\subsection{Equivalent g-Factors in Two Comets}

Table 3 presents emission efficiencies for $\mathrm{OH}$ lines detected in two comets. These equivalent $g$-factors are scaled to a heliocentric distance of $1 \mathrm{AU}$, assuming they vary as the inverse square of the heliocentric distance. Fourteen $(1-0)$ band lines are quantified for 
TABLE 3

Equivalent $g$-Factors at 1 AU for OH Measured in Two Comets

\begin{tabular}{|c|c|c|c|c|}
\hline \multirow[b]{2}{*}{ BAND } & \multirow[b]{2}{*}{ LiNe ID } & \multicolumn{2}{|c|}{ Emission EFficiency $\left(10^{-8} \mathrm{OH}\right.$ photons $\left.\mathrm{s}^{-1}\left[\mathrm{H}_{2} \mathrm{O} \text { molecule }\right]^{-1}\right)$} & \multirow[b]{2}{*}{ RATIO $^{b}$} \\
\hline & & $\mathrm{C} / 2000 \mathrm{WM}_{1}^{\mathrm{a}}$ & $\mathrm{C} / 2004 \mathrm{Q}^{\mathrm{a}}$ & \\
\hline \multirow[t]{17}{*}{$1-0 \ldots \ldots \ldots \ldots \ldots \ldots \ldots \ldots \ldots$} & P4.5 $1^{+}$ & $6.88 \pm(0.18 ; 0.27)$ & $8.36 \pm(0.08 ; 0.45)$ & $0.82 \pm 0.05$ \\
\hline & P4.5 $1^{-}$ & $9.29 \pm(0.20 ; 0.33)$ & $11.41 \pm(0.08 ; 0.61)$ & $0.81 \pm 0.05$ \\
\hline & P6.5 $2^{-}$ & $\ldots$ & $3.53 \pm(0.15 ; 0.23)^{\mathrm{c}}$ & $\ldots$ \\
\hline & P6.5 $2^{+}$ & .. & $3.98 \pm(0.11 ; 0.23)$ & $\ldots$ \\
\hline & P7.5 $1^{-}$ & $\ldots$ & $3.34 \pm(0.51 ; 0.54)^{\mathrm{c}}$ & $\ldots$ \\
\hline & P9.5 $1^{-}$ & $5.14 \pm(0.33 ; 0.36)$ & $3.57 \pm(0.09 ; 0.20)$ & $1.44 \pm 0.13$ \\
\hline & P9.5 $1^{+}$ & $4.47 \pm(0.34 ; 0.36)$ & $4.12 \pm(0.10 ; 0.22)$ & $1.08 \pm 0.10$ \\
\hline & P9.5 $2^{+}$ & $5.27 \pm(0.53 ; 0.55)$ & $4.20 \pm(0.10 ; 0.23)$ & $1.25 \pm 0.15$ \\
\hline & P9.5 2- & $4.21 \pm(0.40 ; 0.42)$ & $3.21 \pm(0.10 ; 0.18)$ & $1.31 \pm 0.15$ \\
\hline & $\mathrm{P} 11.52^{+}$ & $4.22 \pm(0.34 ; 0.36)$ & $4.51 \pm(0.14 ; 0.26)$ & $0.94 \pm 0.10$ \\
\hline & P11.5 $2^{-}$ & $3.24 \pm(0.24 ; 0.26)$ & $2.88 \pm(0.10 ; 0.17)$ & $1.12 \pm 0.11$ \\
\hline & P12.5 $1^{+}$ & $6.09 \pm(0.23 ; 0.29)$ & $5.37 \pm(0.10 ; 0.28)$ & $1.13 \pm 0.08$ \\
\hline & $\mathrm{P} 12.51^{-}$ & $4.46 \pm(0.23 ; 0.27)$ & $3.50 \pm(0.10 ; 0.20)$ & $1.27 \pm 0.11$ \\
\hline & P16.5 $2^{-}$ & $4.94 \pm(0.37 ; 0.40)$ & $3.91 \pm(0.40 ; 0.44)$ & $1.26 \pm 0.18$ \\
\hline & $\mathrm{P} 16.52^{+}$ & $1.81 \pm(0.34 ; 0.34)^{\mathrm{d}}$ & $0.79 \pm(0.14 ; 0.14)$ & $2.29 \pm 0.59$ \\
\hline & $\mathrm{P} 17.51^{-}$ & $5.53 \pm(0.34 ; 0.37)^{\mathrm{d}}$ & $2.68 \pm(0.19 ; 0.23)$ & $2.06 \pm 0.22$ \\
\hline & $\mathrm{P} 17.51^{+}$ & $2.10 \pm(0.38 ; 0.38)^{\mathrm{d}}$ & $0.88 \pm(0.14 ; 0.14)$ & $2.39 \pm 0.57$ \\
\hline \multirow[t]{14}{*}{$2-1$} & P2.5 $1^{+}$ & $\ldots$ & $<3.96$ & $\ldots$ \\
\hline & P2.5 $1^{-}$ & $\ldots$ & $<3.96$ & $\ldots$ \\
\hline & $\mathrm{P} 2.52^{+}$ & $\cdots$ & $<2.36$ & $\cdots$ \\
\hline & $\mathrm{P} 2.52^{-}$ & $\cdots$ & $<2.36$ & $\cdots$ \\
\hline & P3.5 $1^{-}$ & $\ldots$ & $0.71 \pm(0.06 ; 0.07)$ & $\ldots$ \\
\hline & P3.5 $1^{+}$ & $\ldots$ & $2.26 \pm(0.11 ; 0.17)$ & $\ldots$ \\
\hline & P5.5 $2^{+}$ & $<1.26$ & $0.92 \pm(0.16 ; 0.17)$ & $\ldots$ \\
\hline & P5.5 $2^{-}$ & $<1.22$ & $1.29 \pm(0.14 ; 0.15)$ & $\ldots$ \\
\hline & P6.5 $1^{+}$ & $<8.01$ & $0.83 \pm(0.19 ; 0.19)$ & $\ldots$ \\
\hline & P6.5 $1^{-}$ & $<1.57$ & $1.61 \pm(0.12 ; 0.15)$ & $\ldots$ \\
\hline & P8.5 $2^{-}$ & $1.47 \pm(0.24 ; 0.24)$ & $1.53 \pm(0.09 ; 0.11)$ & $0.96 \pm 0.17$ \\
\hline & P8.5 $2^{+}$ & $1.78 \pm(0.23 ; 0.23)$ & $2.10 \pm(0.10 ; 0.14)$ & $0.85 \pm 0.12$ \\
\hline & P9.5 $1^{-}$ & $0.99 \pm(0.25 ; 0.25)$ & $1.23 \pm(0.15 ; 0.16)$ & $0.80 \pm 0.23$ \\
\hline & P9.5 $1^{+}$ & $1.34 \pm(0.28 ; 0.28)$ & $1.43 \pm(0.50 ; 0.50)$ & $0.94 \pm 0.38$ \\
\hline
\end{tabular}

Nоте.-The $g$-factors are assumed to vary as the inverse square of the heliocentric distance.

${ }^{a}$ Two error estimates are given in parentheses: the first one is the stochastic error, reflecting photon noise; the second one is the overall $g$-factor error, including also uncertainty in the $\mathrm{H}_{2} \mathrm{O}$ production rate for the particular comet, and in the growth factors $\left(\mathrm{GF}^{*}\right.$; $\mathrm{GF})$ for the case of $\mathrm{C} / 2004 \mathrm{Q} 2$.

b The $g$-factor ratio of the $\mathrm{C} / 2000 \mathrm{WM}_{1}$ to the $\mathrm{C} / 2004 \mathrm{Q} 2$ measurements; the overall $g$-factor errors are propagated in comparing the two independent data sets.

${ }^{c}$ From the (1-0) band, P6.5 $2^{-}$and P7.5 $1^{-}$are likely blended with $P$-branch $\mathrm{C}_{2} \mathrm{H}_{2}$ lines sampled in the same order. Therefore, the reported $g$-factors should be considered upper limits. The $\mathrm{P} 7.51^{-}$might have additional contamination by $\mathrm{NH}_{2}$.

${ }^{d}$ These values might be overestimated. The quadruplet in order $21\left(\mathrm{P} 16.52^{+}, 2^{-} ; \mathrm{P} 17.51^{+}, 1^{-}\right)$is in the spectral region of $\mathrm{H}_{2} \mathrm{CO}$ transitions. Their $Q$-branch is indicated in the spectra of both $\mathrm{C} / 2000 \mathrm{WM}_{1}$ and $\mathrm{C} / 2004 \mathrm{Q} 2$ (Figs. $2 h$ and $2 i$ ). A recently validated $\mathrm{H}_{2} \mathrm{CO}$ fluorescence model (DiSanti et al. 2006) predicts no "contamination" from $\mathrm{H}_{2} \mathrm{CO}$ for the two middle lines in the $\mathrm{OH}$ quadruplet ( $\mathrm{P} 16.52^{+}$and $\mathrm{P} 17.51^{-}$) and minor contamination for the other two lines, depending on the $\mathrm{H}_{2} \mathrm{CO}$ abundance in the particular comet. However, there is a substantial spectral structure not accounted for in the $\mathrm{H}_{2} \mathrm{CO}$ model in the spectrum of $\mathrm{C} / 2000$ $\mathrm{WM}_{1}$. For this reason, the derived $g$-factors for all four $\mathrm{OH}$ lines might represent upper limits. These questions will be further addressed in a separate paper dedicated to interpretation of formaldehyde emission in several Oort Cloud comets (M. A. DiSanti et al. 2006 , in preparation).

$\mathrm{C} / 2000 \mathrm{WM}_{1}$, and 17 are quantified for $\mathrm{C} / 2004 \mathrm{Q} 2$. In addition, the blended $\mathrm{P} 3.52^{+}$and $2^{-}$transitions are unambiguously detected near $3422 \mathrm{~cm}^{-1}$ in $\mathrm{C} / 2000 \mathrm{WM}_{1}$ (Fig. $2 a$ ). However, their combined $g$-factor cannot be constrained because the terrestrial atmospheric transmittance varies significantly over the narrow spectral range encompassing these lines. But this doublet is definitely strong (and may have some contribution from fluorescence), because it was detected in $\mathrm{C} / 2000 \mathrm{WM}_{1}$ in spite of overall low transmittance $(<40 \%)$. In $\mathrm{C} / 2004 \mathrm{Q} 2$, which has a different Doppler shift, this doublet falls in the core of a strong telluric line.

The weaker (2-1) band lines from the quadruplet of $N^{\prime}=8$ (order 23) are detected in both comets. Order 24 samples the $N^{\prime}=5$ lines, detected only in C/2004 Q2 (the brighter of the two). For $\mathrm{C} / 2000 \mathrm{WM}_{1}, 3 \sigma$ upper limits (based on stochastic noise) are shown in Table 3. Some of the lowest $J^{\prime}$ lines from the (2-1) band $\left(N^{\prime}=1,2\right)$ are sampled in order 25 . For $\mathrm{C} / 2004 \mathrm{Q} 2$, we show equal upper limits for the "+" and "-" component because the two $\Lambda$-doubling components are blended.

The errors shown in Table 3 have both stochastic and systematic components. The former reflects photon noise and is propagated from the uncertainty in flux measurements. The systematic error reflects mainly the uncertainty in the "calibrator," i.e., the directly derived $\mathrm{H}_{2} \mathrm{O}$ production rate. The stochastic and the overall uncertainty are given in parentheses in Table 3. Other sources of uncertainty include possible spectral confusion or marginal identification (see footnotes $\mathrm{c}$ and $\mathrm{d}$ of Table 3 ) for a few $\mathrm{OH}$ lines, and possible contribution from $\mathrm{OH}$ fluorescent emission for the transitions of lowest rotational excitation $\left(N^{\prime}<4\right)$. 
We strongly encourage the reader (especially colleagues who use the reported $g$-factors to obtain $\mathrm{H}_{2} \mathrm{O}$ production rates in comets) to follow the detailed discussion on these issues in Bonev (2005).

\subsection{Comparison of the g-Factor Data Sets from $\mathrm{C} / 2000 \mathrm{WM}_{1}$ and $\mathrm{C} / 2004 \mathrm{Q} 2$}

Table 3 shows that $g$-factors for the (2-1) band in $\mathrm{C} / 2000$ $\mathrm{WM}_{1}$ and $\mathrm{C} / 2004 \mathrm{Q} 2$ are in good agreement, suggesting that the $N^{\prime}=8$ quadruplet could be used to derive water production rates in future comets. This would be useful because at least some of these lines can be sampled simultaneously with $\mathrm{CH}_{4}$, even with a single-order spectrometer having a very narrow spectral grasp. The same is true for the $N^{\prime}=11$ quadruplet of the $(1-0)$ band.

The derived $g$-factor for the strong P17.5 $1^{-}$line (order 21) in $\mathrm{C} / 2000 \mathrm{WM}_{1}$ is significantly larger than the corresponding value in C/2004 Q2. This raises a concern because we wish to use the aforementioned line for extracting mixing ratios between $\mathrm{H}_{2} \mathrm{CO}$ and $\mathrm{H}_{2} \mathrm{O}$. The discrepancy is resolved if the $\mathrm{C} / 2000 \mathrm{WM}_{1}$ value is overestimated because of spectral overlap with unknown features (see Table 3, footnote d). This assumption is strengthened by the agreement between water production rates in C/2001 A2 (2001 July 9) derived from the $\mathrm{OH}^{*} \mathrm{P} 17.51^{-}$line using the $g$-factor from C/2004 Q2 $\left([4.2 \pm 0.6] \times 10^{28}\right.$ molecules s $^{-1}$; Gibb et al. 2006) and independently from the $\mathrm{H}_{2} \mathrm{O}$ hot-band emission near $2.9 \mu \mathrm{m}\left([3.8 \pm 0.4] \times 10^{28}\right.$ molecules s ${ }^{-1}$; Dello Russo et al. 2005).

\subsection{Updated g-Factors for the $\mathrm{OH}$ Quadruplet near $3046 \mathrm{~cm}^{-1}$}

We have now evaluated $\mathrm{OH} g$-factors for the $N^{\prime}=11$ quadruplet near $3046 \mathrm{~cm}^{-1}$ for six observing dates in four comets, including C/1999 H1 (Lee), C/2001 A2 (LINEAR), C/2000 WM and C/2004 Q2. Emission efficiencies for the first two comets were reported in B04. Table 4 presents weighted means of all available $g$-factors for the $N^{\prime}=11$ quadruplet. The uncertainties in these weighted means account for the observed variation in $\mathrm{PE}$ efficiencies derived for different comets. Note that the $\mathrm{C} / 2000 \mathrm{WM}_{1}$ and C/2004 Q2 $g$-factors have fallen mostly within the already established range of the measurements in C/1999 H1 and C/2001 A2, so the overall error has been reduced compared to the results in $\mathrm{B} 04$.

\section{SUMMARY}

Near-UV and radio observations, conducted for decades, provide self-consistent databases for cometary $\mathrm{OH}$. A third database is now emerging from spectroscopic detections of hydroxyl at IR wavelengths via rovibrational transitions. Most of these transitions result from photodissociative excitation of $\mathrm{H}_{2} \mathrm{O}$ giving rise to "prompt" emission.

The IR database for $\mathrm{OH}$ can be used in two principal ways: (1) as an indirect tool for obtaining $\mathrm{H}_{2} \mathrm{O}$ production in comets in the IR simultaneously with the production of trace constituents $\left(\mathrm{CH}_{4}\right.$, $\mathrm{H}_{2} \mathrm{CO}$, etc.); and (2) as an observational constraint to models predicting the rotational distribution of rovibrationally excited $\mathrm{OH}$ produced by water photolysis (Paper II). It should be emphasized that the $\mathrm{UV}$ and radio data for $\mathrm{OH}$ sample the extended cometary coma, where emissions from most daughter fragments are typically observed. On the other hand, observations of IR OH prompt emission are biased toward the inner coma (the closest several hundred to $\sim 10^{3} \mathrm{~km}$ from the nucleus), where most parent volatiles are also sampled via their rovibrational transitions.

For this paper, we performed a quantitative analysis of IR OH emission in comets $\mathrm{C} / 2000 \mathrm{WM}_{1}$ (LINEAR) and C/2004 Q2
TABLE 4

Equivalent $g$-Factors at 1 AU for the OH PE (1-0) Band Quadruplet near $3046 \mathrm{~cm}^{-1}$ Averaged over Measurements in Four Comets

\begin{tabular}{|c|c|c|}
\hline Line ID & $\begin{array}{c}\nu_{0} \\
\left(\mathrm{~cm}^{-1}\right)\end{array}$ & Emission Efficiency $^{a}$ \\
\hline 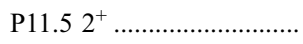 & 3047.4576 & $4.07 \pm 0.31$ \\
\hline P11.5 $2^{-} \ldots \ldots \ldots \ldots \ldots \ldots \ldots \ldots$ & 3046.5508 & $3.00 \pm 0.19$ \\
\hline $\mathrm{P} 12.51^{+}$.. & 3044.4280 & $5.41 \pm 0.28$ \\
\hline P12.5 $1^{-} \ldots \ldots \ldots \ldots \ldots \ldots \ldots$ & 3043.2137 & $3.62 \pm 0.28$ \\
\hline
\end{tabular}

a The $g$-factor has the same unit as in Table 3 . The values given present weighted means of emission efficiencies obtained from six observations (four comets), including the results from Table 1 in Bonev et al. (2004) and from Table 3 in this paper. The uncertainties are $1 \sigma$ standard (variance) errors; formal $95 \%$ confidence intervals correspond to $2.57 \sigma$, taking into account the small-number statistics.

(Machholz). We detected $\mathrm{H}_{2} \mathrm{O}$ and multiple lines of $\mathrm{OH}$ simultaneously. Our principal results are as follows:

1. We derived equivalent $g$-factors of more than $20 \mathrm{OH}$ lines sampled in the $L$ band in two comets. Our data set of individual line $g$-factors is now expanded significantly compared to the study of Bonev et al. (2004), which reported emission efficiencies for only four $\mathrm{OH}$ rovibrational transitions. The new $g$-factors can be used to obtain $\mathrm{H}_{2} \mathrm{O}$ production rates in other comets, based on measured $\mathrm{OH}$ line fluxes.

2. We showed that the spatial distribution of the $\mathrm{P} 4.51^{+}$and $1^{-}$emission intensity in $\mathrm{C} / 2001 \mathrm{WM}_{1}$ is typical for a parent volatile and tracks the distribution of the parent $\mathrm{H}_{2} \mathrm{O}$. Therefore, the dominant excitation mechanism of these lines is expected to be prompt emission, despite their low rotational excitation.

3. Although the general notion that the $\mathrm{OH}$ prompt emission faithfully tracks the spatial distribution of the parent is valid, comet $\mathrm{C} / 2004 \mathrm{Q} 2$ presents a specific case in which the apparent spatial profiles of $\mathrm{OH}^{*}$ and $\mathrm{H}_{2} \mathrm{O}$ are different in their central regions. Such a difference could indicate that $\mathrm{OH}$ is underproduced in the innermost coma, for example, from opacity in the solar UV radiation responsible for water photolysis (Appendix A). This effect should increase with increasing water production rate and will be tested in future studies.

Measurements of quantitative mixing ratios for trace parent volatiles with respect to the dominant native species $\left(\mathrm{H}_{2} \mathrm{O}\right)$ are critical to establishing a chemical taxonomy for comets. Simultaneous measurement of production rates for $\mathrm{H}_{2} \mathrm{O}$ and other volatiles eliminates many systematic errors and can produce highly reliable mixing ratios. At infrared wavelengths, this can be accomplished via $\mathrm{OH}$ prompt emission comeasured with molecules of interest $\left(\mathrm{CH}_{4}, \mathrm{H}_{2} \mathrm{CO}\right.$, $\mathrm{HCN}$, etc.), especially when direct measurements of $\mathrm{H}_{2} \mathrm{O}$ are not available (e.g., if using instruments with limited free spectral range).

We thank our anonymous referee for providing helpful comments. We also thank Geronimo L. Villanueva and Philip B. James for useful discussions on the presented results, and Harold Weaver for his assistance with the $\mathrm{C} / 2000 \mathrm{WM}_{1}$ observations. This work was supported by the NASA Planetary Astronomy Program under RTOP 344-32-30-07 to M. J. M., and RTOP 344-32-98 to M. A. D.; by NASA Planetary Atmospheres Program grants NAG5-10795 and NAG5-12285 to N. D. R.; and by RTOP 344-33-55 to M. A. D. K. M.-S. acknowledges support from 
TABLE 5

$\mathrm{H}_{2} \mathrm{O}$ Optical Depth Effects in the UV (“Strawman” Model)

\begin{tabular}{|c|c|c|c|c|c|c|}
\hline Comet & $\begin{array}{c}Q\left(\mathrm{H}_{2} \mathrm{O}\right)^{\mathrm{a}} \\
\left(10^{28} \text { molecules s }^{-1}\right)\end{array}$ & $\begin{array}{c}\Delta \\
(\mathrm{AU})\end{array}$ & $\begin{array}{l}R_{c}(\mathrm{Ly} \alpha)^{\mathrm{b}} \\
(\mathrm{km})\end{array}$ & $\begin{array}{l}R_{c}(\mathrm{FAB}) \\
\quad(\mathrm{km})\end{array}$ & $\begin{array}{l}\text { Spatial Pixel Size } \\
(\mathrm{km})\end{array}$ & $\begin{array}{l}\text { Spatial Extent for } \mathrm{NCR}^{\mathrm{d}} \\
\qquad(\mathrm{km})\end{array}$ \\
\hline $\mathrm{C} / 2000 \mathrm{WM}_{1} \ldots \ldots \ldots \ldots \ldots \ldots$ & 2.1 & 0.357 & 3 & 1 & 51 & 231 \\
\hline 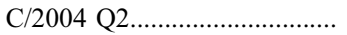 & 26.0 & 0.394 & 44 & 13 & 57 & 255 \\
\hline 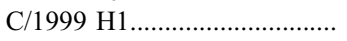 & 14.3 & 1.348 & 24 & 7 & 194 & 871 \\
\hline $\mathrm{C} / 2001 \mathrm{~A} 2 \ldots \ldots \ldots$ & 4.3 & 0.282 & 8 & 2 & 40 & 182 \\
\hline
\end{tabular}

${ }^{a}$ Calculated from analysis of $\mathrm{H}_{2} \mathrm{O}$ nonresonant fluorescence. The production rates for $\mathrm{C} / 2000 \mathrm{WM}_{1}$ and $\mathrm{C} / 2004 \mathrm{Q} 2$ are taken from Bonev (2005); the production rates for C/1999 H1 and C/2001 A2 are taken from Dello Russo et al. (2005).

b The critical radius $\left(R_{c}\right)$ is calculated separately for $\mathrm{Ly} \alpha$ and for the peak absorption coefficient in the first absorption band of $\mathrm{H}_{2} \mathrm{O}$ (see text).

${ }^{c}$ Pixel size over the spatial dimension for NIRSPEC $=0.198\left(\operatorname{arcsec} \operatorname{pixel}^{-1}\right) \times 725.3\left(\mathrm{~km} \mathrm{arcsec}^{-1} \mathrm{AU}^{-1}\right) \times \Delta(\mathrm{AU})$, where $\Delta$ is the geocentric distance.

d NCR designates the "nucleus-centered region" as defined in the main text ( $\S$ 6); it corresponds to a flux measurement over the central (with respect to the peak gas emission) nine spatial pixels (i.e., \pm 4 pixels with respect to the central one).

the National Science Foundation RUI Program (0407052). The data presented herein were obtained at the W. M. Keck Observatory, operated as a scientific partnership among the California Institute of Technology, University of California at Los Angeles, and NASA. This observatory was made possible by the generous financial support of the W. M. Keck Foundation. The authors wish to recognize and acknowledge the very significant cultural role and reverence that the summit of Mauna Kea has always had within the indigenous Hawaiian community. We are most fortunate to have the opportunity to conduct observations from this mountain.

\section{APPENDIX A}

\section{OPTICAL DEPTH EFFECTS AS A PLAUSIBLE EXPLANATION FOR THE APPARENT DIFFERENCE BETWEEN THE SPATIAL PROFILES OF $\mathrm{H}_{2} \mathrm{O}$ AND OH* IN C/2004 Q2}

Optical depth effects in the UV are one plausible explanation for the observed difference between the $\mathrm{H}_{2} \mathrm{O}$ and $\mathrm{OH}^{*}$ spatial distributions in $\mathrm{C} / 2004 \mathrm{Q} 2(\S 5)$. Increasing UV opacity would lower the rate of $\mathrm{H}_{2} \mathrm{O}$ photolysis in the near-nucleus region and hence the effective $g$-factor for PE. The spatial distribution of $\mathrm{OH}$ would not track the distribution of the parent in that case. The critical question is at what distance from the nucleus the optical depth in the UV radiation responsible for dissociation of $\mathrm{H}_{2} \mathrm{O}$ becomes unity. This distance will be referred to as critical radius $\left(R_{c}\right)$ and is estimated as follows.

For a spherically symmetric outflow and for distances $(r)$ to the nucleus much smaller than the $\mathrm{H}_{2} \mathrm{O}$ dissociation scale length $(\sim 70,000 \mathrm{~km})$, the number density of $\mathrm{H}_{2} \mathrm{O}$ is given by the expression

$$
n(r)=\frac{Q}{4 \pi V r^{2}} \mathrm{~m}^{-3}
$$

where $V$ is the expansion velocity and $Q$ is the $\mathrm{H}_{2} \mathrm{O}$ production rate. The value of $Q$ is based on fluxes that are averaged from measurements equidistant to either side of the nucleus (see Appendix B and references therein). As has been demonstrated (Xie \& Mumma 1996), this approach minimizes the effects of possible asymmetric outflow.

The column density $N_{\text {col }}$ from a certain distance $R$ from the nucleus along the line to the Sun is

$$
N_{\text {col }}(R)=\int_{R}^{\infty} n(r) d r=\frac{Q}{4 \pi V R} \mathrm{~m}^{-2}
$$

The optical depth at a given UV frequency is

$$
\tau_{\mathrm{UV}}(R)=\sigma_{\mathrm{abs}} N_{\mathrm{col}}(R),
$$

where $\sigma_{\text {abs }}$ is the absorption cross section of $\mathrm{H}_{2} \mathrm{O}$ for that particular frequency. The critical radius $R_{c}$ is defined for $\tau_{\mathrm{UV}}\left(R_{c}\right)=1$ :

$$
R_{c}=\frac{\sigma_{\mathrm{abs}} Q}{4 \pi V} .
$$

For this calculation, we adopted a value of the expansion velocity of $8 \times 10^{2} \mathrm{~m} \mathrm{~s}^{-1}$ (at $1 \mathrm{AU}$ ). The resulting $R_{c}$ would be the lower limit, as the coma expansion velocity in the first $\sim 100 \mathrm{~km}$ from the nucleus might be less than our assumed value (see Combi et al. 2004). We adopt values for $\sigma_{\mathrm{abs}}$ from Budzien et al. (1994): $16 \mathrm{Mbarn}\left(1 \mathrm{Mbarn}=10^{-18} \mathrm{~cm}^{2}\right)$ for Ly $\alpha$ and $5 \mathrm{Mbarn}$ at the peak of the first absorption band $(\sim 167 \mathrm{~nm})$.

We calculated critical radii for the four comets for which spatial distributions of $\mathrm{OH} \mathrm{PE}$ and $\mathrm{H}_{2} \mathrm{O}$ fluorescent emission have been directly compared (Table 5). These critical radii are compared with the pixel size ( $\mathrm{km}$ ) along the slit and the corresponding extent 
of the nucleus-centered region (always taken to be 9 spatial pixels). We emphasize that Table 5 provides only simple ("strawman" model) estimates for the relative importance of UV opacity for the included comets. Precise modeling would face (among other factors) uncertainties in quantifying the outflow from the nucleus of C/2004 Q2 (in order to obtain more realistic number densities), and in quantifying the relative contributions of different UV frequencies to the production of each excited state of OH leading to an observed PE.

$\mathrm{C} / 2004 \mathrm{Q} 2$ has the highest $\mathrm{H}_{2} \mathrm{O}$ production rate among the comets included in Table 5 and also was observed relatively close (0.394 AU) to Earth. The critical radius for this comet corresponds to a few tens of $\mathrm{km}$ from the nucleus (depending on the photon frequency for dissociation of water). The signal from this innermost region in the coma dominates the nucleus-centered flux measurement (because the emission from a parent volatile is strongly peaked at the nucleus). Moreover, this signal is not confined to the central pixel, but is spread over a few pixels because of atmospheric "seeing." Based on this, the possibility of the observed difference between the distributions of $\mathrm{OH}^{*}$ and $\mathrm{H}_{2} \mathrm{O}$ in C/2004 Q2 being caused by UV optical depth effects cannot be ruled out. Near the centers of the spatial profiles, the PE efficiency could be lower because the dissociation rates are "damped" by $\mathrm{H}_{2} \mathrm{O}$ opacity. In the wings of the profiles, the coma is optically thin at UV wavelengths, $\mathrm{H}_{2} \mathrm{O}$ dissociation should be efficient, and OH PE is expected to track the parent, as seen in Figures 5-7 (§5).

There is an apparent correlation between the level of excitation sampled by the $\mathrm{OH}$ lines and the growth factor correction between nucleus-centered and terminal production rate (Appendix B). The significance of this correlation cannot be validated based on the three C/2004 Q2 spatial profiles alone (which have only moderate S/N). But if UV opacity indeed is the cause for underproducing $\mathrm{OH}$ close to the nucleus, the effect should not be the same for all $\mathrm{OH}$ lines. It will depend on the optical depth at the frequencies responsible for producing the $\mathrm{OH}$ excited state giving rise to a particular transition.

\section{APPENDIX B}

\section{$\mathrm{H}_{2} \mathrm{O}$ AND $\mathrm{OH}^{*} Q$-CURVES AND GROWTH FACTOR MEASUREMENTS}

\section{B1. BACKGROUND}

Here we review the background for and show an example of deriving the growth factor parameters for $\mathrm{H}_{2} \mathrm{O}$ and $\mathrm{OH}^{*}\left(\mathrm{GF}\right.$ and $\mathrm{GF}^{*}$, respectively). The complete analysis relevant to this topic can be found in Bonev (2005).

We first note that differences between spatial distributions of various species are reflected in the appearance of their corresponding " $Q$-curves" and in the ratios of "terminal" to "nucleus-centered" production rates (e.g., Dello Russo et al. 1998; DiSanti et al. 1999, 2001). A spherical production rate is defined by formula (2) in the main text $(\S 6.3)$, where $F\left(\mathrm{OH}^{*}\right)$ can be replaced by a flux measurement within a given aperture of an arbitrary emission. A $Q$-curve is defined as the trend of apparent (i.e., without a growth factor correction) spherical production rate $(Q)$ with the projected distance from the nucleus. The production rates along the $Q$-curve are proportional to the ratio between measured flux and the adopted $g$-factor.

Figure $8 a$ shows a "symmetric" $Q$-curve (e.g., DiSanti et al. 1999; Gibb et al. 2003; Mumma et al. 2003) constructed from the flux contained in the spatial profile of $\mathrm{H}_{2} \mathrm{O}$ in $\mathrm{C} / 2004 \mathrm{Q} 2$ (e.g., Fig. 6). In the symmetric $Q$-curve, each production rate represents a flux measurement over 3 spatial pixels $\left(0^{\prime \prime} 198\right.$ pixel $\left.^{-1}\right)$. The first measurement corresponds to the 3 pixels centered on the peak of the spatial profile. Away from the nucleus, the measured flux is averaged over two 3 pixel extracts, equidistant from the nucleus on each side.

A $Q$-curve can also be constructed from the spatial profile of $\mathrm{OH}^{*}$, assuming a constant (independent of projected distance from the nucleus) equivalent $g$-factor $\left(\mathrm{OH}\right.$ photons s $\left.{ }^{-1}\left[\mathrm{H}_{2} \mathrm{O} \text { molecule }\right]^{-1}\right)$ for PE. A $Q$-curve for $\mathrm{OH}\left(N^{\prime}=8\right.$, 9; spatial profile on Fig. 6) is shown in Figure $8 b$.

The $\mathrm{H}_{2} \mathrm{O}$ and $\mathrm{OH}^{*} Q$-curves show very similar (although not identical) trends. The apparent increase in production rate with projected distance from the nucleus is well understood; it is caused by observing-related effects such as slit losses due to atmospheric seeing and/or comet drift (e.g., Dello Russo et al. 1998; DiSanti et al. 2001). Such effects lead to production rates that are systematically underestimated close to the nucleus. However, these effects have a much smaller influence on flux measurements taken in the wings of the spatial profiles, where surface brightness varies slowly. Consequently, both the $\mathrm{H}_{2} \mathrm{O}$ and $\mathrm{OH}^{*} Q$-curves reach a terminal value at about $1^{\prime \prime}$ from the nucleus.

We define a terminal production rate $\left(Q_{\text {term }}\right)$ as the weighted mean of individual production rates calculated outside the region where slit losses are important. We also define nucleus-centered production rate $\left(Q_{\mathrm{nc}}\right)$ as the spherical production rate corresponding to a flux measurement from the 9 spatial pixels centered on the nucleus (not to be confused with the first point from the $Q$-curve, which corresponds to only the 3 central pixels and is most severely affected by slit losses). The ratio $Q_{\text {term }} / Q_{\mathrm{nc}}$ is called a growth factor and is commonly used to correct nucleus-centered fluxes for slit losses. Because the same $g$-factor (emission efficiency) is used throughout the $Q$-curve, the growth factor is independent of the assumed value of $g$.

The similar shape of the $\mathrm{OH}^{*}$ and $\mathrm{H}_{2} \mathrm{O} Q$-curves is a consequence of two factors: (1) although not identical to the $\mathrm{H}_{2} \mathrm{O}$ spatial distribution, the $\mathrm{OH}^{*}$ profile is still parent-like in the sense that it peaks at the nucleus and is steeper than a distribution dominated by a fluorescent component); and (2) $\mathrm{OH}^{*}$ and $\mathrm{H}_{2} \mathrm{O}$ are observed simultaneously within the same NIRSPEC setting and therefore their measured fluxes have been affected identically by the aforementioned observing-related effects.

The different (in their central parts) spatial profiles of $\mathrm{H}_{2} \mathrm{O}$ and $\mathrm{OH}^{*}$ (Figs. 5-7) cause differences in growth factors (Table 6). These differences cannot be related to the observing conditions because, as mentioned above, all lines are detected within the same instrument setting. However, if OH is underproduced in the innermost coma (see $\S 5$ and Appendix A), the actual PE $g$-factor there would be smaller than in the terminal region of the $Q$-curve. Then, adopting the same $g$-factor for the nucleus-centered and the terminal region would result in an underestimated ratio (flux/g-factor) near the nucleus, leading to an additional underestimate in the production rate independent of slit losses. However, the terminal value from the $\mathrm{OH}^{*} Q$-curve (or nucleus-centered flux with a proper growth factor correction) may still be taken to represent the production of $\mathrm{H}_{2} \mathrm{O}$. 


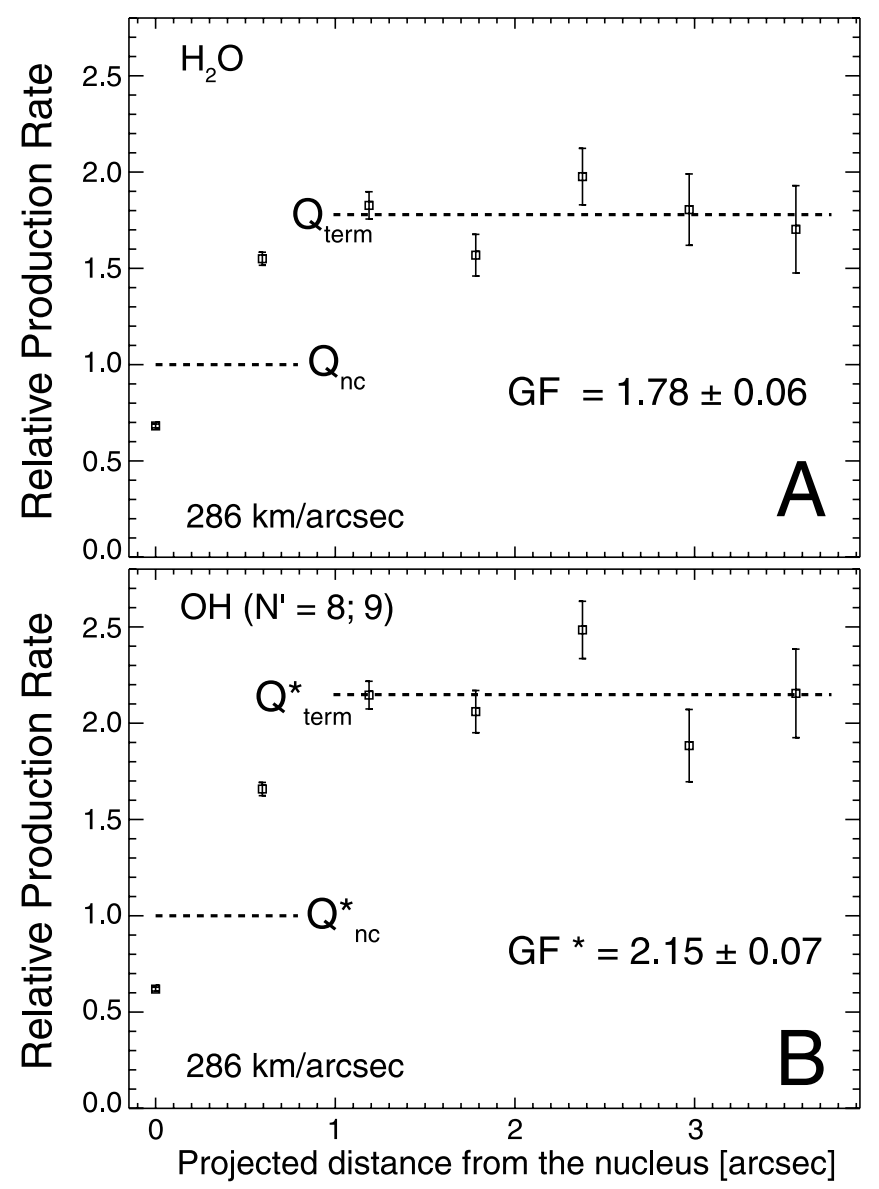

Fig. 8.- $Q$-curves constructed from the $(a) \mathrm{H}_{2} \mathrm{O}$ and $(b) \mathrm{OH}$ spatial profiles shown in Fig. 6. The spatial ranges representing the "terminal" $\left(Q_{\text {term }}, Q_{\text {term }}^{*}\right)$ and "nucleus-centered" $\left(Q_{\mathrm{nc}}, Q_{\mathrm{nc}}^{*}\right)$ production rates are shown as dashed lines. These $Q$-curves are normalized to the nucleus-centered production rates to emphasize the different growth factors for $\mathrm{H}_{2} \mathrm{O}$ and $\mathrm{OH}^{*}$. [See the electronic edition of the Journal for a color version of this figure.]

\section{B2. GROWTH FACTORS FOR $\mathrm{H}_{2} \mathrm{O}$ AND $\mathrm{OH}^{*}$}

Table 6 reports our derived values of growth factors for $\mathrm{H}_{2} \mathrm{O}$ and $\mathrm{OH}^{*}$. For $\mathrm{C} / 2000 \mathrm{WM}_{1}, \mathrm{GF}^{*} \approx \mathrm{GF}$, consistent with the congruency of the spatial distributions. Growth factor corrections are not necessary in this case, and the $\mathrm{OH} g$-factors may be obtained from nucleuscentered production rates. This is analogous to our commonly used approach of obtaining mixing ratios between a given parent volatile $\left(\mathrm{CH}_{4}, \mathrm{HCN}\right.$, etc.) and $\mathrm{H}_{2} \mathrm{O}$ from nucleus-centered extracts when both molecules are observed within the same setting.

For C/2004 Q2, the spatial distribution of hydroxyl is flatter than that of $\mathrm{H}_{2} \mathrm{O}$ in the central part of the profiles, so $\mathrm{GF}^{*}>\mathrm{GF}$. Directly measured growth factors are available from the combined fluxes of the (1-0) band lines from $N^{\prime}=3,8$, and 9 , and from $N^{\prime}=11$. Because the $\mathrm{GF}^{*}$ values for $N^{\prime}=8$ and 9 , and those for $N^{\prime}=11$ do not differ significantly, a weighted mean growth factor is used for them. Adequate spatial analysis for lines from the remaining multiplets is prevented by inadequate $\mathrm{S} / \mathrm{N}$, even after individual line fluxes are combined. In these cases, we adopt growth factors corresponding to emission lines of similar rotational excitation. We assume that the $\mathrm{GF}^{*}$ value from $N^{\prime}=8,9$, and 11 is valid also for the (1-0) band lines with $N^{\prime}=16$ (order 21). For the (1-0) band lines from $N^{\prime}=6$ (order 25), a weighted mean of growth factors from lower $\left(N^{\prime}=3\right)$ and higher $\left(N^{\prime}=8,9\right.$, and 11) excitation lines is adopted. For the (2-1) band lines with $N^{\prime}=1$ and 2 (order 25), we assign the growth factor value from $N^{\prime}=3$, because they are also of low rotational excitation. Finally, for the (2-1) band lines with $N^{\prime}=8$ (order 23), we assume the same growth factor as for the high-excitation $(1-0)$ band lines $\left(N^{\prime}=8,9\right.$, and 11$)$.

TABLE 6

Growth FACTORS FOR $\mathrm{H}_{2} \mathrm{O}$ AND OH

\begin{tabular}{|c|c|c|}
\hline Comet & Emission & $Q$-curve Growth Factor \\
\hline \multirow[t]{4}{*}{ C/2004 Q2 } & $\mathrm{H}_{2} \mathrm{O}$ & $1.78 \pm 0.06$ \\
\hline & $\mathrm{OH}^{*}, \mathrm{P} 4.51^{+}, 1^{-}$ & $1.99 \pm 0.05$ \\
\hline & $\mathrm{OH}^{*}, \mathrm{P} 9.51^{+}, 1^{-}, 2^{+}, 2^{-}$ & $2.15 \pm 0.07$ \\
\hline & $\mathrm{OH}^{*}, \mathrm{P} 11.52^{+}, 2^{-} ; \mathrm{P} 12.51^{+}, 1^{-}$ & $2.27 \pm 0.07$ \\
\hline \multirow{3}{*}{$\mathrm{C} / 2000 \mathrm{WM}_{1} \ldots \ldots$} & $\mathrm{H}_{2} \mathrm{O}$ & $1.55 \pm 0.03$ \\
\hline & $\mathrm{OH}^{*}, \mathrm{P} 4.51^{+}, 1^{-}$ & $1.57 \pm 0.07$ \\
\hline & $\mathrm{OH}^{*}, \mathrm{P} 11.52^{+}, 2^{-} ; \mathrm{P} 12.51^{+}, 1^{-}$ & $1.47 \pm 0.04$ \\
\hline
\end{tabular}


The limited spatial information in C/2004 Q2 is not sufficient to either justify or reject the aforementioned assumptions. Therefore, these assumptions represent the most serious systematic uncertainty affecting the $\mathrm{OH} g$-factors for this comet. This uncertainty will be addressed long term in two ways: (1) by comparing the spatial distributions of simultaneously detected $\mathrm{OH}$ and $\mathrm{H}_{2} \mathrm{O}$ in future comets observed in circumstances similar to C/2004 Q2, i.e., production rate exceeding $10^{29}$ molecules $\mathrm{s}^{-1}$ and small geocentric distance (allowing the innermost coma to be spatially resolved); and (2) by comparing (when possible) $\mathrm{H}_{2} \mathrm{O}$ production rates derived independently from $\mathrm{OH}^{*}$ (using the $\mathrm{C} / 2004 \mathrm{Q} 2 \mathrm{~g}$-factors) and from $\mathrm{H}_{2} \mathrm{O}$ hot-band emission (e.g., $\S$ 6.5).

\section{REFERENCES}

Abrams, M. C., Davis, S. P., Rao, M. L. P., \& Engleman, R., Jr. 1990, ApJ, 363, 326 A'Hearn, M. F., Millis, R. L., Schleicher, D. G., Osip, D. J., \& Birch, P. V. 1995, Icarus, 118, 223

Alexander, M. H., et al. 1988, J. Chem. Phys., 89, 1749

Bockelée-Morvan, D., \& Crovisier, J. 1989, A\&A, 216, 278

Bockelée-Morvan, D., Crovisier, J., \& Gérard, E. 1990, A\&A, 238, 382

Bonev, B. P. 2005, Ph.D. thesis, Univ. Toledo, http://astrobiology.gsfc.nasa.gov/ Bonev_thesis.pdf

Bonev, B. P., \& Mumma, M. J. 2006, ApJ, 653, 789 (Paper II)

Bonev, B. P., Mumma, M. J., Dello Russo, N., Gibb, E. L., DiSanti, M. A., \& Magee-Sauer, K. 2004, ApJ, 615, 1048 (B04)

Brooke, T. Y., Tokunaga, A. T., Weaver, H. A., Crovisier, J., Bockelée-Morvan, D., \& Crisp, D. 1996, Nature, 383, 606

Budzien, S. A., Festou, M. C., \& Feldman, P. D. 1994, Icarus, 107, 164

Colom, P., Gérard, E., Crovisier, J., Bockelée-Morvan, D., Biver, N., \& Rauer, H. 1997, Earth Moon Planets, 78, 37

Combes, M., et al. 1986, Nature, 321, 266

Combi, M. R., Harris, W. M., \& Smyth, W. H. 2004, in Comets II, ed. M. C. Festou, H. U. Keller, \& H. A. Weaver (Tucson: Univ. Arizona Press)

Crovisier, J. 1989, A\&A, 213, 459

Crovisier, J., Colom, P., Gérard, E., \& Bockelée-Morvan, D. 2002a, Earth Moon Planets, 90, 369

Crovisier, J., Colom, P., Gérard, E., Bockelée-Morvan, D., \& Bourgois, G. 2002b, A\&A, 393, 1053

Dello Russo, N., Bonev, B. P., DiSanti, M. A., Mumma, M. J., Gibb, E. L., Magee-Sauer, K., Barber, R. J., \& Tennyson, J. 2005, ApJ, 621, 537

Dello Russo, N., DiSanti, M. A., Magee-Sauer, K., Gibb, E. L., Mumma, M. J., Barber, R. J., \& Tennyson, J. 2004, Icarus, 168, 186

Dello Russo, N., DiSanti, M. A., Mumma, M. J., Magee-Sauer, K., \& Rettig, T. W. 1998, Icarus, 135, 377

Dello Russo, N., Mumma, M. J., DiSanti, M. A., Magee-Sauer, K., Novak, R., \& Rettig, T. W. 2000, Icarus, 143, 324

Delsemme, A. H. 1998, Planet. Space Sci., 46, 111

Despois, D., Gérard, E., Crovisier, J., \& Kazes, I. 1981, A\&A, 99, 320

Dieke, G. H., \& Crosswhite, H. M. 1962, J. Quant. Spectrosc. Radiat. Transfer, 2, 97

DiSanti, M. A., Bonev, B. P., Magee-Sauer, K., Dello Russo, N., Mumma, M. J., Reuter, D. C., \& Villanueva, G. L. 2006, ApJ, 650, 470

DiSanti, M. A., Mumma, M. J., Dello Russo, N., \& Magee-Sauer, K. 2001, Icarus, 153, 361

DiSanti, M. A., Mumma, M. J., Dello Russo, N., Magee-Sauer, K., Novak, R., \& Rettig, T. W. 1999, Nature, 399, 662

Feldman, P. D. 1997, Earth Moon Planets, 79, 145
Feldman, P. D., Cochran, A. L., \& Combi, M. R. 2004, in Comets II, ed. M. C. Festou, H. U. Keller, \& H. A. Weaver (Tucson: Univ. Arizona Press)

Festou, M. C., \& Feldman, P. D. 1987, in Exploring the Universe with the IUE Satellite, ed. Y. Kondo \& W. Wamsteker, (Dordrecht: Reidel)

Festou, M. C., Keller, H. U., \& Weaver, H. A. 2004, in Comets II, ed. M. C. Festou, H. U. Keller, \& H. A. Weaver (Tucson: Univ. Arizona Press)

Gibb, E. L., DiSanti, M. A., Magee-Sauer, K., Dello Russo, N., Bonev, B. P., \& Mumma, M. J. 2006, Icarus, submitted

Gibb, E. L., Mumma, M. J., Dello Russo, N., DiSanti, M. A., \& Magee-Sauer, K. 2003, Icarus, 165, 391

Harich, S. A., Hwang, D. W. H., Yang, X., Lin, J. J., Yang, X., \& Dixon, R. N. 2000, J. Chem. Phys., 113, 10073

Herzberg, G. 1988, The Spectra and Structure of Simple Free Radicals (New York: Dover)

Kawakita, H., Watanabe, J., Furusho, R., Fuse, T., \& Boice, D. C. 2005, ApJ, 623, L49

Kunde, V. G., \& Maguire, W. C. 1974, J. Quant. Spectrosc. Radiat. Transfer, 14,803

Magee-Sauer, K., Mumma, M. J., DiSanti, M. A., \& Dello Russo, N. 2002, J. Geophys. Res., 107, 6

Magee-Sauer, K., Mumma, M. J., DiSanti, M. A., Dello Russo, N., \& Rettig, T. W. 1999, Icarus, 142, 498

Maillard, J. P., Chauville, J., \& Mantz, A. W. 1976, J. Mol. Spectrosc., 63, 120

McLean, I. S., et al. 1998, Proc. SPIE, 3354, 566

Mumma, M. J. 1982, in Vibrational-Rotational Spectroscopy for Planetary Atmospheres, ed. M. J. Mumma, K. Fox, \& J. Hornstein (NASA CP-2223; Washington: NASA), 717

Mumma, M. J., DiSanti, M. A., Dello Russo, N., Magee-Sauer, K., Gibb, E. L., \& Novak, R. 2003, Adv. Space Res., 31, 2563

Mumma, M. J., Weaver, H. A., Larson, H. P., Williams, M., \& Davis, D. S. 1986, Science, 232, 1523

Mumma, M. J., et al. 2001, ApJ, 546, 1183

Rothman, L. S., et al. 1992, J. Quant. Spectrosc. Radiat. Transfer, 48, 469

Schleicher, D. G., \& A'Hearn, M. F. 1982, ApJ, 258, 864 1988, ApJ, 331, 1058

Schloerb, F. P., De Vries, C. H., Lovell, A. J., Irvine, W. M., Senay, M., \& Wootten, H. A. 1997, Earth Moon Planets, 78, 45S

Swings, P., Elvey, C. T., \& Babcock, H. W. 1941, ApJ, 94, 320

Weaver, H. A., Feldman, P. D., A'Hearn, M. F., Arpigny, C., Brandt, J. C., \& Stern, S. A. 1999, Icarus, 141, 1

Weaver, H. A., \& Mumma, M. J. 1984, ApJ, 276, 782

Xie, X., \& Mumma, M. J. 1996, ApJ, 464, 457 